\title{
Determinants of parathyroid hormone response to vitamin D supplementation: a systematic review and meta-analysis of randomised controlled trials
}

\author{
Nazanin Moslehi ${ }^{1}$, Sakineh Shab-Bidar ${ }^{2 *}$, Parvin Mirmiran ${ }^{3}$, Farhad Hosseinpanah ${ }^{4}$ and Fereidoun Azizi ${ }^{5}$ \\ ${ }^{1}$ Nutrition and Endocrine Research Center, Research Institute for Endocrine Sciences, Shabid Beheshti University of Medical \\ Sciences, 9395-4763 Tebran, Iran \\ ${ }^{2}$ Department of Community Nutrition, School of Nutritional Sciences and Dietetics, Tehran University of Medical Sciences, \\ 14155-6117 Tehran, Iran \\ ${ }^{3}$ Department of Clinical Nutrition and Dietetics, Faculty of Nutrition Sciences and Food Technology, National Nutrition \\ and Food Technology Research Institute, Shabid Beheshti University of Medical Sciences, 19395-4741 Tebran, Iran \\ ${ }^{4}$ Obesity Research Center, Research Institute for Endocrine Sciences, Shabid Beheshti University of Medical Sciences, \\ 19395-4763 Tehran, Iran \\ ${ }^{5}$ Endocrine Research Center, Research Institute for Endocrine Sciences, Shabid Beheshti University of Medical Sciences, \\ 19395-4763 Tehran, Iran
}

(Submitted 10 April 2015 - Final revision received 23 July 2015 - Accepted 24 July 2015 - First published online 4 September 2015)

\section{Abstract}

This systematic review aimed to assess the determinants of the parathyroid hormone (PTH) level response to vitamin D supplementation. We searched Medline, Google Scholar and the reference lists of previous reviews. All randomised controlled trials (RCT) on vitamin D supplementation that involved apparently healthy human subjects with a report of PTH were selected. Potential studies were screened independently and in duplicate. Results are summarised as mean differences with $95 \%$ confidence intervals. Quality assessment, subgroup analysis, meta-analysis and meta-regression analysis were carried out. Thirty-three vitamin D supplementation RCT were included. Vitamin D supplementation significantly raised circulating 25-hydroxyvitamin D $(25(\mathrm{OH}) \mathrm{D})$ with significant heterogeneity among studies with a pooled mean difference (PMD) of $15.5 \mathrm{ng} / \mathrm{ml}$ (test for heterogeneity: $P<0.001$ and $I^{2}=97.3 \%$ ). Vitamin D supplementation significantly reduced PTH level with PMD of $-8.0 \mathrm{pg} / \mathrm{ml}$, with significant heterogeneity ((test for heterogeneity: $P<0 \cdot 001$ ) and the $I^{2}$ value was $97 \cdot 3 \%$ ). In the subgroup analyses, the optimum treatment effect for PTH was observed with Ca doses of $600-1200 \mathrm{mg} / \mathrm{d}(-22 \cdot 48 \mathrm{pg} / \mathrm{ml})$, after the duration of a $>12$-month trial $(-18.36 \mathrm{pg} / \mathrm{ml})$, with low baseline $25(\mathrm{OH}) \mathrm{D}$ concentration of $<20 \mathrm{ng} / \mathrm{ml}(-16.70 \mathrm{pg} / \mathrm{ml})$ and in those who were overweight and obese $(-18.11 \mathrm{pg} / \mathrm{ml})$. Despite the present meta-analysis being hindered by some limitations, it provided some interesting evidence, suggesting that suppression of PTH level needs higher vitamin D intake $(75 \mu \mathrm{g} / \mathrm{d})$ than the current recommendations and longer durations (12 months), which should be taken into account for nutritional recommendations.

\section{Key words: Cholecalciferol: Vitamin D: Parathyroid hormone: Meta-analyses: Randomised controlled trials}

The central role of vitamin D in the maintenance of bone health is well documented. Recent evidence reports a link between lower serum 25-hydroxyvitamin D (25(OH)D) concentrations and a variety of chronic illnesses ${ }^{(1)}$. Low serum $25(\mathrm{OH}) \mathrm{D}$ is considered to be the best indicator of overall vitamin $\mathrm{D}$ deficiency. Severe vitamin D deficiency (serum $25(\mathrm{OH}) \mathrm{D}<25 \mathrm{nmol} / \mathrm{l})$ ) is associated with increased bone resorption, accelerated cortical bone loss and increased fractures ${ }^{(2)}$.

Health authorities around the world recommend widely variable supplementation strategies for adults ${ }^{(3)}$. The reference daily intake is $10 \mu \mathrm{g} / \mathrm{d}$ for children between 0 and 12 months of age, $15 \mu \mathrm{g} / \mathrm{d}$ for males and females aged between 1 and
70 years and $20 \mu \mathrm{g} / \mathrm{d}$ for people older than 70 years to prevent fracture $^{(4)}$. According to our previous meta-analysis, to obtain an optimal vitamin D status of $50 \mathrm{nmol} / 1$ in adults, $20 \mu \mathrm{g}$ is sufficient ${ }^{(5)}$.

Serum parathyroid hormone (PTH) has been studied as a surrogate marker of vitamin D status. There are too many publications that show the inverse relationship between serum PTH and serum 25(OH)D. Moreover, many studies have tried to define a level of serum $25(\mathrm{OH}) \mathrm{D}$ at which serum PTH levels decreased and reached a plateau. However, the reported thresholds are highly variable, varying between 10 and $50 \mathrm{ng} / \mathrm{ml}$. It is important to note that some other studies failed to

Abbreviations: 25(OH)D, 25-hydroxyvitamin D; MD, mean difference; PTH, parathyroid hormone; PMD, pooled mean difference; RCT, randomised controlled trial.

* Corresponding author: S. Shab-Bidar, fax +98 21889559 79, email s_shabbidar@tums.ac.ir 
demonstrate definite thresholds ${ }^{(6)}$. Based on the results of some reports, there are certain possible factors affecting $\mathrm{PTH}$ response to vitamin D supplementation, including method of PTH measurement, BMI, age, renal function, $\mathrm{Ca}$ intake and baseline level of serum $25(\mathrm{OH}) \mathrm{D}$ and $\mathrm{PTH}^{(7)}$. To the best of our knowledge, except for one systemic review ${ }^{(8)}$, there has been no systematic review and meta-analysis thus far thoroughly addressing the question 'at what level of serum 25(OH)D level does PTH reach the threshold and what are the determinants of PTH level?'

Therefore, in context of a systematic review and meta-analysis on randomised controlled trials (RCT), we conducted a metaanalysis and a meta-regression analysis on randomised clinical trials to explain existing heterogeneity regarding determinants of PTH level response to vitamin D supplementation in adults.

\section{Methods}

\section{Search strategy and identification of the studies}

The study was carried out using a detailed protocol developed in advance, including predefined research questions and objectives, search strategy, study eligibility criteria, the methods of data extraction and statistical analysis. All the variables for subgroup analysis were predefined. We used the statement of Preferred Reporting Items for Systematic Reviews and Meta-Analyses (PRISMA) for reporting the present study ${ }^{(9)}$.

We searched the English-language medical literature published between January 1980 and November 2013 using the Medline and Google scholar database. We used structured search strategy using various combinations of keywords for vitamin D (online Supplementary Table S1). We also checked the references of recent systematic reviews that investigated the effects of oral intake or intramuscular injection of vitamin D supplements to find additional relevant studies.

RCT on vitamin D (with or without Ca) supplementation that involved apparently healthy human subjects or patients whose disease has no effect on vitamin D metabolism were included in the analysis. RCT were selected because the greatest validity and causal interference can be found in such studies ${ }^{(10)}$.

We included studies that fulfilled the following criteria: (1) vitamin $\mathrm{D}_{3} \geq 10 \mu \mathrm{g} / \mathrm{d}$ administered orally per se or with Ca on a daily basis (inclusion of vitamin $\mathrm{D}_{3}$ and $\mathrm{D}_{2}$ was chosen, although the Institute of Medicine dietary recommended intakes (IOM) DRI committee has defined DRI based on studies with vitamin $\mathrm{D}_{3}^{(11)}$ and there is evidence that vitamin $\mathrm{D}_{3}$ increases serum $25(\mathrm{OH}) \mathrm{D}$ more efficiently than vitamin $\left.\mathrm{D}_{2}^{(12,13)}\right)$; (2) separately reported serum or plasma $25(\mathrm{OH}) \mathrm{D}$ levels in intervention and control groups; (3) separately reported serum or plasma PTH levels in intervention and control groups; (4) a minimum duration of 6 weeks, because serum 25(OH)D concentrations reach equilibrium after at least $6-8$ weeks in adults ${ }^{(5,14,15)}$.

The exclusion criteria included the following: (1) use of compounds such as vitamin D metabolites $(25(\mathrm{OH}) \mathrm{D}$ and $1,25(\mathrm{OH}) 2 \mathrm{D})$ and analogues (e.g. $\alpha$-calcidol) co-administered; (2) studies carried out in infants, children, adolescents and pregnant or lactating women; (3) studies in which vitamin D was administered as fortified food; (4) interventions that included patients with chronic renal disease, chronic heart disease, cirrhosis and hyperparathyroidism; (5) RCT that used cluster randomisations and cross-over studies; (6) trials without control or placebo groups; (7) studies published in languages other than English, because effect sizes did not differ significantly in language-restricted meta-analyses compared with language-inclusive ones ${ }^{(16)}$, as well as lower quality in the non-English medical literature ${ }^{(17)}$; (8) repeated studies, if the results of the trials had been published in more than one article, we used the reporting results on the largest sample of individuals, or the most recently published or the more detailed results; (9) abstracts, because of insufficient information; and (10) dissertations, because the full text was rarely available.

Variations between the extracted studies regarding supplement dosage, frequency of supplementation and use of either intramuscular or oral delivery methods were acceptable and were not excluded.

\section{Data collection and synthesis}

To identify and include eligible studies in the final analysis, two authors (S. S.-B. and N. M.), independently, reviewed the titles of the articles extracted by the search for relevance to our topic, and then we retrieved the full-text articles of those that were potentially relevant. Screening list was used to select eligible articles. Backward search was carried out through published reviews previously and those published after our search date.

Moreover, the quality control of the articles was carried out independently by two authors (S. S.-B. and N. M.). Discrepancies between authors were solved by consensus with the third author (F. H.). We included only data reported in the study, because recall bias in the information or data might be provided by authors $^{(18)}$.

All relevant information were abstracted on study characteristics including the following: first author, publication year, country of origin, study design, the number of participants in each arm of RCT, age, sex, the dose of supplement, frequency supplement use, duration of supplementation, type of supplement used in the RCT, mean values and standard deviations of the baseline and final values for 25(OH)D and PTH in the treatment and control arms at each time point and for each vitamin D dose. In studies with different doses, we included each dose as a separate study and used the dose subgroups $v$. controls separately. If a study had several intervals for follow-up measurements of $25(\mathrm{OH}) \mathrm{D}$, we included each time interval as a separate study. If studies had subgroups such as sex, they were included in our study as a separate study.

For any other information pertinent to the review, such as potential confounders to the RCT (i.e. the season of implementing the intervention and BMI), the analysis technique chosen to assess serum $25(\mathrm{OH}) \mathrm{D}$ and the dropout rates were also noted when reported.

\section{Quality of assessment}

We assessed the quality of studies using Jadad scales ${ }^{(19)}$, which include the following four items: reporting of randomisation method, allocation concealment, blinding of outcome assessment and completeness of follow-up (online Supplementary Table S2). 


\section{Statistical analysis}

The mean difference (MD) of achieved levels of 25(OH)D and PTH between the intervention and control groups for each individual study was calculated. If the standard error was reported for variation of mean, we calculated SD by dividing $\mathrm{SE} / n^{2}$. For the calculation of the standard deviation from the range and confidence intervals, we divided the range by 5.88 and CI by 3.92.

Cochran's $Q$ statistic and the $I^{2}$ statistic were used to assess statistical heterogeneity in the meta-analysis ${ }^{(20)}$. Both the fixedeffects and random-effects models were used to calculate the pooled MD of PTH level in response to vitamin D. In this review, we present results from the random-effects model because significant heterogeneity was identified among studies ${ }^{(21)}$

Potential sources of heterogeneity were also investigated in predefined subgroups. We assessed treatment effects in preset subgroups: (1) dose ( $\leq 20$ and $>20 \mu \mathrm{g}$ ); (2) vitamin supplementation with or without Ca; (3) Ca dose ( no Ca, 400-600 and 600-1200); (4) duration (<3, 3-6, 6-12 and >12 months); (5) baseline $25(\mathrm{OH}) \mathrm{D}$ ( $<20$ or $\geq 20 \mathrm{ng} / \mathrm{ml})$; (6) baseline PTH ( $\leq 6 \cdot 0,6 \cdot 1-38 \cdot 0,38 \cdot 1-49 \cdot 0$ and $\geq 49 \cdot 0$ ); (7) BMI ( $>25,25-30$ and $\geq 30 \mathrm{~kg} / \mathrm{m}^{2}$ ); (8) sex (men, women, both); (9) age ( $<50$ and $\geq 50$ years); and (10) study quality (low quality $v$. high quality).

The meta-regression was used to analyse factors within a trial that best explained the variance in MD of PTH. Using metaregression, we analysed the effects of daily doses of vitamin $\mathrm{D}$, duration of the trial, baseline $25(\mathrm{OH}) \mathrm{D}$, baseline PTH, BMI and age on MD.

We performed ancillary analyses including curve estimation models for weighted mean difference (WMD) of serum levels of PTH according to dose and duration and baseline 25(OH)D and PTH as continuous variables.

A cumulative meta-analysis ${ }^{(22)}$ was also performed to determine that the evidence was consistent over time. Influence analysis was carried out to show that no particular trial affected the pooled effect size.

A formal statistical test on publication bias was not meaningful because we excluded studies with sample sizes $<30$. However, publication bias was analysed by funnel plot analysis (online Supplementary Fig. S1) and Egger's regression asymmetry test for the included studies ${ }^{(23,24)}$. In our analysis, the summary estimate for PTH was statistically significant when we included Suzuki et al.'s study ${ }^{(25)}$ that reported a large WMD. We then considered this study to be a possible outlier, and thus excluded the study from our analysis. All tests were two-tailed, and a probability level $<0.05$ was considered to be statistically significant. Statistics were performed using Stata version 12.0 (Stata Corporation) and SPSS version 18.

\section{Results}

\section{Study characteristics}

Of the 2360 studies identified, thirty-three studies ${ }^{(26-58)}$ including fifty intervention groups with 7574 participants ( $n 3851$ in intervention group and $n 3663$ in placebo group) were selected for the present meta-analysis (Fig. 1). All of them were RCT;

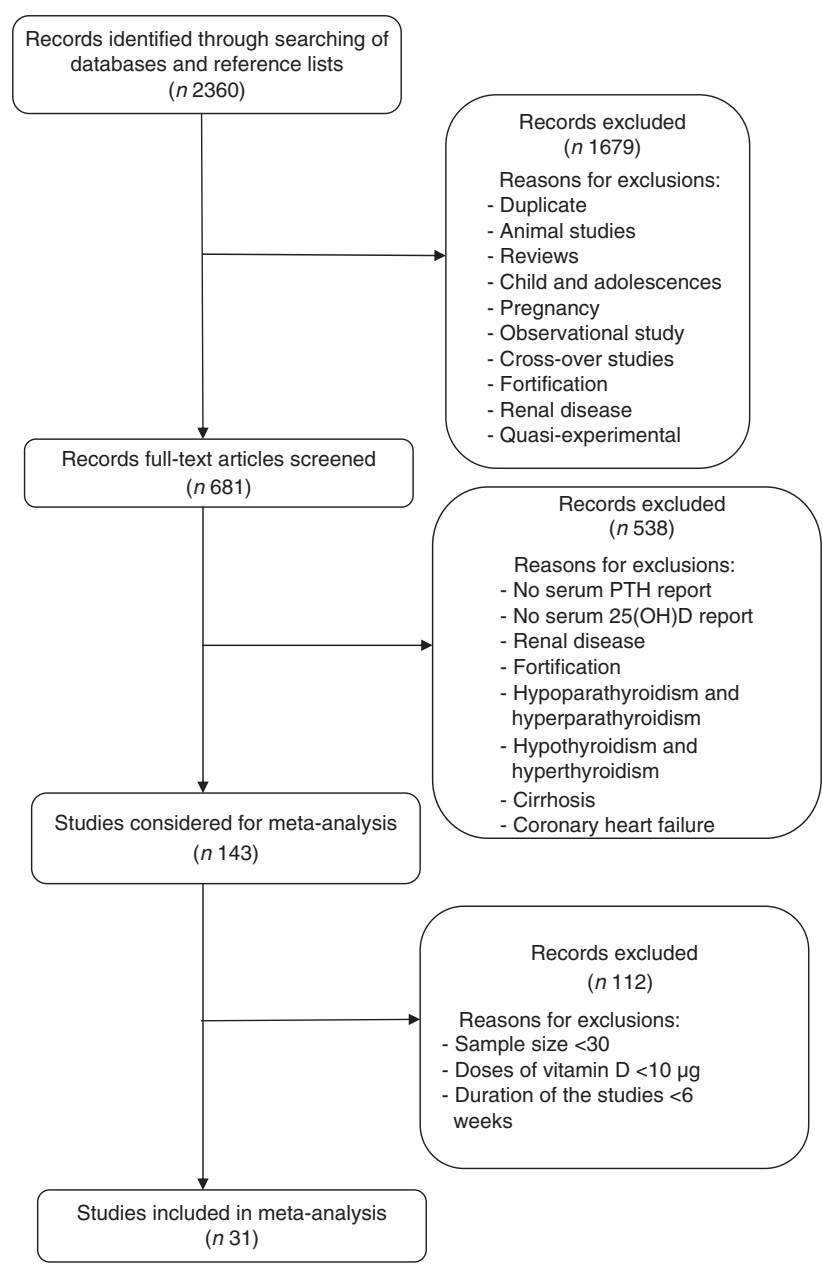

Fig. 1. Flow chart of study selection for inclusion in the systematic review. 25(OH)D, 25-hydroxyvitamin D; PTH, parathyroid hormone.

however, sixteen studies did not clarify the method of randomisation $^{(26-31,33,35,36,41-44,47,50,53)}$. The mean age of the participants ranged from twenty-one to 85 years. The daily doses of vitamin D supplementation varied from 10 to $250 \mu \mathrm{g} / \mathrm{d}$; only two studies supplemented vitamin D in the form of ergocaciferol ${ }^{(26,51)}$, and two studies did not report the form of vitamin D supplement used ${ }^{(27,34)}$. The duration of supplementation ranged from 2 to 36 months. The majority of studies were conducted on women or on women and men together; only two studies were conducted only on men ${ }^{(30,34)}$. Using the Jadad scale, $81.8 \%$ of the studies were of high quality (scores $\geq 3$ ), with an average score of 3.6. Six studies were considered to be of low quality (scores $\leq 2)^{(26,28,31,41,47,53)}$ (online Supplementary Table S2). Study characteristics are summarised in Table 1.

\section{Meta-analysis for serum vitamin $D$ responses}

The pooled mean difference (PMD) of 25(OH)D from the pre-trial was $+15 \cdot 5 \mathrm{ng} / \mathrm{ml}(-5$ to $+40 \mathrm{ng} / \mathrm{ml})$ in the intervention group. The forest plot with $\mathrm{MD}$ in post-trial $25(\mathrm{OH}) \mathrm{D}$ concentrations between intervention and placebo groups and their $95 \%$ confidence intervals are illustrated in Fig. 2. As there 
Table 1. Study and participant characteristics

\begin{tabular}{|c|c|c|c|c|c|c|c|c|c|c|c|}
\hline Author & Year & Country & $\begin{array}{l}\text { Total } \\
\text { number }\end{array}$ & $\begin{array}{l}\text { Mean age } \\
\text { (years) }\end{array}$ & Participants & Sex & Treatment & $\begin{array}{c}\text { Trial } \\
\text { duration } \\
\text { (months) }\end{array}$ & $\begin{array}{c}\text { Daily dose } \\
(\mathrm{Ca}(\mathrm{mg}) / \\
\text { vitamin } \mathrm{D}(\mu \mathrm{g}))\end{array}$ & $\begin{array}{c}\text { Final MD of } \\
\text { serum } 25(\mathrm{OH}) \mathrm{D}^{*} \\
(\mathrm{ng} / \mathrm{ml})\end{array}$ & $\begin{array}{c}\text { Final MD of } \\
\text { serum PTH† } \\
(\mathrm{pg} / \mathrm{ml})\end{array}$ \\
\hline Chapuy ${ }^{(26)}$ & 1987 & France & 38 & 74 & Elderly people & 3 & $\mathrm{Ca}+$ vitamin $\mathrm{D}_{2}$ & 6 & $1000 / 20$ & $14 \cdot 60$ & -37.90 \\
\hline Dawson-Hughes $^{(27)}$ & 1991 & USA & 124 & 61 & Elderly women & 2 & $\mathrm{Ca}+$ vitamin $\mathrm{D}$ & 12 & $400 / 12 \cdot 5$ & 12.60 & -2.90 \\
\hline Chapuy ${ }^{(28)}$ & 1992 & France & 73 & 84 & Elderly people & 2 & $\mathrm{Ca}+$ vitamin $\mathrm{D}_{3}$ & 6 & $1200 / 20$ & 27.00 & $-15 \cdot 0$ \\
\hline Chapuy ${ }^{(28)}$ & 1992 & France & 73 & 84 & Elderly people & 2 & $\mathrm{Ca}+$ vitamin $\mathrm{D}_{3}$ & 12 & $1200 / 20$ & 32.00 & $-27 \cdot 0$ \\
\hline Chapuy ${ }^{(28)}$ & 1992 & France & 73 & 84 & Elderly people & 2 & $\mathrm{Ca}+$ vitamin $\mathrm{D}_{3}$ & 18 & $1200 / 20$ & 31.00 & $-26 \cdot 0$ \\
\hline $\mathrm{Ooms}^{(29)}$ & 1995 & Holland & 177 & 80 & Elderly women & 2 & Vitamin $D_{3}$ & 12 & 10 & $15 \cdot 60$ & -5.45 \\
\hline Dawson-Hughes ${ }^{(30)}$ & 1997 & USA & 167 & 71 & Elderly people & 2 & $\mathrm{Ca}+$ vitamin $\mathrm{D}_{3}$ & 36 & $500 / 17.5$ & 34.72 & $-16 \cdot 4$ \\
\hline Dawson-Hughes ${ }^{(30)}$ & 1997 & USA & 146 & 70 & Elderly people & 1 & $\mathrm{Ca}+$ vitamin $\mathrm{D}_{3}$ & 36 & $500 / 17.5$ & 32.43 & $-10 \cdot 0$ \\
\hline Krieg $^{(31)}$ & 1999 & Switzerland & 34 & 84 & Elderly institutionalised women & 2 & $\mathrm{Ca}+$ vitamin $\mathrm{D}_{3}$ & 12 & $1000 / 22$ & 21.50 & $-23 \cdot 30$ \\
\hline Krieg $^{(31)}$ & 1999 & Switzerland & 34 & 84 & Elderly institutionalised women & 2 & $\mathrm{Ca}+$ vitamin $\mathrm{D}_{3}$ & 24 & $1000 / 22$ & 20.82 & $-31 \cdot 70$ \\
\hline Hunter ${ }^{(32)}$ & 2000 & London & 64 & 59 & Women & 2 & Vitamin $D_{3}$ & 3 & 20 & 3.00 & -2.30 \\
\hline Hunter ${ }^{(32)}$ & 2000 & London & 64 & 59 & Women & 2 & Vitamin $D_{3}$ & 6 & 20 & 11.70 & -1.60 \\
\hline Pfeifer ${ }^{(33)}$ & 2001 & Germany & 74 & 75 & Elderly women & 2 & $\mathrm{Ca}+$ vitamin $\mathrm{D}_{3}$ & 2 & $1200 / 20$ & 8.19 & -6.45 \\
\hline Kenny ${ }^{(34)}$ & 2003 & Farmington, CT & 33 & 76 & Men & 1 & $\mathrm{Ca}+$ vitamin $\mathrm{D}$ & 6 & $500 / 25$ & 12.00 & -19.00 \\
\hline Grados $^{(35)}$ & 2003 & France & 95 & 74 & Ambulatory elderly women & 2 & $\mathrm{Ca}+$ vitamin $\mathrm{D}_{3}$ & 12 & $1000 / 20$ & 27.34 & $-38 \cdot 70$ \\
\hline Brazier $^{(37)}$ & 2005 & France & 95 & 74 & Elderly women & 2 & $\mathrm{Ca}+$ vitamin $\mathrm{D}_{3}$ & 12 & $1000 / 20$ & 18.04 & -7.50 \\
\hline Talwar ${ }^{(38)}$ & 2007 & Mineola, NY & 104 & 60 & Healthy black postmenopausal women & 2 & Vitamin $D_{3}$ & 3 & 20 & 12.92 & -1.40 \\
\hline Talwar ${ }^{(38)}$ & 2007 & Mineola, NY & 104 & 60 & Healthy black postmenopausal women & 2 & Vitamin $D_{3}$ & 24 & 50 & 9.72 & $1 \cdot 10$ \\
\hline Talwar ${ }^{(38)}$ & 2007 & Mineola, NY & 104 & 60 & Healthy black postmenopausal women & 2 & Vitamin $D_{3}$ & 27 & 50 & 16.80 & 0.80 \\
\hline Pittas $^{(39)}$ & 2007 & Boston & 45 & 71 & Adults with IFG & 3 & $\mathrm{Ca}+$ vitamin $\mathrm{D}_{3}$ & 36 & $500 / 17.5$ & 11.60 & -7.45 \\
\hline Pittas $^{(39)}$ & 2007 & Boston & 108 & 71 & Adults without IFG & 3 & $\mathrm{Ca}+$ vitamin $\mathrm{D}_{3}$ & 36 & $500 / 17.5$ & 16.52 & -13.91 \\
\hline Sneve ${ }^{(40)}$ & 2008 & Norway & 116 & 46 & Obese or overweight adults & 3 & $\mathrm{Ca}+$ vitamin $\mathrm{D}_{3}$ & 12 & $500 / 142 \cdot 9$ & $25 \cdot 36$ & $-13 \cdot 73$ \\
\hline Sneve ${ }^{(40)}$ & 2008 & Norway & 106 & 48 & Obese or overweight adults & 3 & $\mathrm{Ca}+$ vitamin $\mathrm{D}_{3}$ & 12 & $500 / 71 \cdot 4$ & $15 \cdot 32$ & -13.55 \\
\hline Chel $^{(41)}$ & 2008 & Holland & 45 & 84 & Elderly subjects & 3 & Vitamin $D_{3}$ & 4 & 15 & 8.20 & -8.18 \\
\hline Chel $^{(41)}$ & 2008 & Holland & 48 & 84 & Elderly subjects & 3 & Vitamin $D_{3}$ & 4 & 15 & 13.80 & -9.09 \\
\hline Chel $^{(41)}$ & 2008 & Holland & 46 & 84 & Elderly subjects & 3 & Vitamin $D_{3}$ & 4 & 15 & 14.24 & -19.09 \\
\hline Björkman ${ }^{(42)}$ & 2008 & Finland & 77 & 84 & Bedridden older patients & 2 & $\mathrm{Ca}+$ vitamin $\mathrm{D}_{3}$ & 6 & $500 / 10$ & 9.08 & -14.40 \\
\hline Björkman ${ }^{(42)}$ & 2008 & Finland & 73 & 84 & Bedridden older patients & 2 & $\mathrm{Ca}+$ vitamin $\mathrm{D}_{3}$ & 6 & $500 / 30$ & $19 \cdot 28$ & -19.90 \\
\hline Cashman ${ }^{(43)}$ & 2008 & UK & 57 & 30 & Healthy young & 3 & Vitamin $D_{3}$ & 6 & 10 & 9.04 & $-5 \cdot 70$ \\
\hline Cashman $^{(43)}$ & 2008 & UK & 53 & 30 & Healthy young & 3 & Vitamin $D_{3}$ & 6 & 15 & 12.64 & $-13 \cdot 20$ \\
\hline Pfeifer ${ }^{(44)}$ & 2009 & Germany & 121 & 76 & Community-dwelling seniors & 3 & $\mathrm{Ca}+$ vitamin $\mathrm{D}_{3}$ & 12 & $1000 / 20$ & 10.80 & -4.00 \\
\hline Pfeifer ${ }^{(44)}$ & 2009 & Germany & 121 & 76 & Community-dwelling seniors & 3 & $\mathrm{Ca}+$ vitamin $\mathrm{D}_{3}$ & 20 & $1000 / 20$ & 4.00 & 11.00 \\
\hline Zitterman $^{(45)}$ & 2009 & Germany & 82 & 47 & Healthy overweight subjects & 3 & Vitamin $D_{3}$ & 12 & $83 \cdot 3$ & 17.40 & -5.00 \\
\hline Islam ${ }^{(46)}$ & 2010 & Finland & 40 & 22 & Apparently healthy subjects & 2 & $\mathrm{Ca}+$ vitamin $\mathrm{D}_{3}$ & 12 & $600 / 10$ & 14.08 & $-5 \cdot 50$ \\
\hline Islam ${ }^{(46)}$ & 2010 & Finland & 40 & 22 & Apparently healthy subjects & 2 & Vitamin $D_{3}$ & 12 & 10 & 13.68 & $-2 \cdot 90$ \\
\hline$J^{\prime o r d e}{ }^{(47)}$ & 2010 & Norway & 62 & 46 & Obese or overweight subjects & 3 & $\mathrm{Ca}+$ vitamin $\mathrm{D}_{3}$ & 12 & $500 / 71.43$ & $15 \cdot 18$ & -5.27 \\
\hline Jorde $^{(47)}$ & 2010 & Norway & 63 & 46 & Obese or overweight subjects & 3 & $\mathrm{Ca}+$ vitamin $\mathrm{D}_{3}$ & 12 & $500 / 142.85$ & 30.58 & 6.55 \\
\hline $\operatorname{Lips}^{(48)}$ & 2010 & Holland & 113 & 79 & Older subjects & 3 & $\mathrm{Ca}+$ vitamin $\mathrm{D}_{3}$ & 4 & $500 / 30$ & 12.50 & -6.00 \\
\hline Grimnes $^{(49)}$ & 2011 & Norway & 49 & 52 & Participants with low serum vitamin $D$ & 3 & Vitamin $D_{3}$ & 6 & $142 \cdot 9$ & 39.92 & -5.64 \\
\hline Chung ${ }^{(50)}$ & 2011 & Korea & 82 & 65 & Osteoporotic adults & 3 & $\mathrm{Ca}+$ vitamin $\mathrm{D}_{3}$ & 4 & $500 / 20$ & 14.32 & -8.80 \\
\hline Sokol ${ }^{(51)}$ & 2012 & USA & 45 & 55 & Coronary artery disease patients & 2 & Vitamin $D_{2}$ & 3 & 178.6 & 10.00 & -6.50 \\
\hline Ponda ${ }^{(52)}$ & 2012 & New York & 76 & 48 & Adults & 3 & Vitamin $D_{3}$ & 2 & 250 & 28.40 & -14.00 \\
\hline Harris $^{(53)}$ & 2012 & Boston & 43 & 57 & $\begin{array}{c}\text { Overweight or obese with pre- or early } \\
\text { diabetes }\end{array}$ & 3 & $\mathrm{Ca}+$ vitamin $\mathrm{D}_{3}$ & 3 & $600 / 100$ & 17.48 & $-14 \cdot 90$ \\
\hline Larsen $^{(54)}$ & 2012 & Denmark & 55 & 60 & Hypertensive patients & 3 & Vitamin $D_{3}$ & 5 & 75 & 24.00 & $-7 \cdot 80$ \\
\hline Kjærgaard $^{(55)}$ & 2012 & Norway & 120 & 53 & Adults with depression & 3 & Vitamin $D_{3}$ & 6 & $142 \cdot 9$ & 38.08 & -9.09 \\
\hline Salehpour ${ }^{(56)}$ & 2012 & Iran & 39 & 38 & Adults & 2 & Vitamin $D_{3}$ & 3 & 25 & 9.40 & -4.55 \\
\hline Goswami ${ }^{(57)}$ & 2012 & India & 43 & 21 & Healthy women & 2 & $\mathrm{Ca}+$ vitamin $\mathrm{D}_{3}$ & 6 & $1000 / 214.3$ & 19.28 & -23.90 \\
\hline Goswami ${ }^{(57)}$ & 2012 & India & 43 & 21 & Healthy women & 2 & Vitamin $D_{3}$ & 6 & 214.3 & $22 \cdot 20$ & $-16 \cdot 60$ \\
\hline Suzuki ${ }^{(58)}$ & 2013 & Japan & 55 & 73 & Parkinson disease & 3 & Vitamin $D_{3}$ & 12 & 30 & 31.92 & -15.00 \\
\hline
\end{tabular}

1, male; 2, female; 3, male and female; 25(OH)D, 25-hydroxyvitamin D; MD, mean difference; PTH, parathyroid hormone; IFG, impaired fasting glucose.

* Final serum $25(\mathrm{OH}) \mathrm{D}$ in the intervention group minus final serum $25(\mathrm{OH}) \mathrm{D}$ in the placebo group.

$\dagger$ Final serum PTH in the intervention group minus final serum PTH in the placebo group. 
Study ID

Chapuy MC 1987

Dawson-Hughes B 1991

Chapuy MC 1992

Chapuy MC 1992

Chapuy MC 1992

Ooms ME 1995

Dawson-Hughes B 1997

Dawson-Hughes B 1997

Krieg MA 1999

Krieg MA 1999

Hunter D 2000

Hunter D 2000

Pfeifer M 2001

Kenny AM 2003

Grados F 2003

Bischoff HA 2003

Brazier M 2005

Talwar SA 2007

Talwar SA 2007

Talwar SA 2007

Pittas AG 2007

Pittas AG 2007

Sneve M 2008

Sneve M 2008

Chel M 2008

Chel M 2008

Björkman M 2008

Björkman M 2008

Chel M 2008

Cashman KD 2008

Cashman KD 2008

Pfeifer M 2009

Pfeifer M 2009

Zitterman A 2009

Islam MZ 2010

Islam MZ 2010

Jorde R 2010

Jorde R 2010

Lips P 2010

Grimness G 2011

Chung HY 2011

Sokol SI 2012

Ponda MP 2012

Harris SS 2012

Larsen T 2012

Kjærgaard M 2012

Salehpour A 2012

Goswami R 2012

Goswami R 2012

Overall
Difference in means

$(95 \% \mathrm{Cl})$

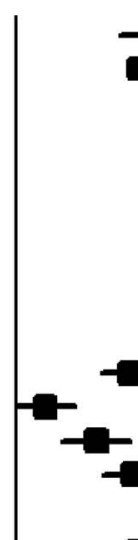

Difference
in means

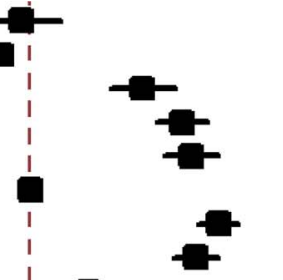

\begin{tabular}{l}
$10 \cdot 62,18.58$ \\
\hline
\end{tabular}

$12.60 \quad 12.37,12.83$

$27.00 \quad 23 \cdot 70,30 \cdot 30$

$31.00 \quad 28.36,33.64$

$32.00 \quad 29 \cdot 20,34 \cdot 80$

$15.60 \quad 15.25,15.95$

$34.72 \quad 32 \cdot 67,36 \cdot 77$

$32.43 \quad 30 \cdot 20,34 \cdot 67$

$21.50 \quad 21.04,21.96$

$20 \cdot 82 \quad 20 \cdot 20,21 \cdot 44$

$11.70 \quad 8.72,14.68$

$3.00 \quad 0.02,5.98$

$8.19 \quad 4 \cdot 76,11 \cdot 62$

$12.00 \quad 8.99,15.01$

$27.34 \quad 24.82,29.86$

$14.80 \quad 11 \cdot 29,18.31$

$18.04 \quad 16.88,19.20$

$12.92 \quad 10.75,15.09$

$16.80 \quad 14 \cdot 15,19 \cdot 45$

$9 \cdot 72 \quad 7.51,11.93$

$11.60 \quad 7.95,15.25$

$16.52 \quad 14.17,18.87$

$25.36 \quad 23.06,27 \cdot 66$

$15.32 \quad 12.95,17.69$

$8.20 \quad 6.12,10.28$

$13.80 \quad 11.84,15 \cdot 76$

$19 \cdot 28 \quad 16 \cdot 36,22 \cdot 20$

$9.08 \quad 6.21,11.95$

$14.24 \quad 11.93,16.55$

$12.64 \quad 10.26,15.02$

$9.04 \quad 7 \cdot 14,10.94$

$10.80 \quad 8.88,12.72$

$4.00 \quad 2.53,5.47$

$17 \cdot 40 \quad 11 \cdot 58,23 \cdot 22$

$14.08 \quad 10.89,17 \cdot 27$

$13 \cdot 68 \quad 10 \cdot 49,16 \cdot 87$

$15.18 \quad 12.06,18.30$

$30 \cdot 58 \quad 27 \cdot 48,33 \cdot 68$

$12.50 \quad 10.09,14.91$

$39.92 \quad 36 \cdot 45,43.39$

$14 \cdot 32 \quad 11 \cdot 60,17 \cdot 04$

$10.00 \quad 8 \cdot 22,11 \cdot 78$

$28 \cdot 40 \quad 25 \cdot 30,31 \cdot 50$

$17 \cdot 48 \quad 13 \cdot 66,21 \cdot 30$

$24 \cdot 00 \quad 20 \cdot 70,27 \cdot 30$

$38.08 \quad 35.67,40.49$

$9 \cdot 40 \quad 4 \cdot 59,14 \cdot 21$

$19 \cdot 28 \quad 16 \cdot 23,22 \cdot 33$

$22.20 \quad 19.48,24.92$

$15.52 \quad 15.36,15.67$

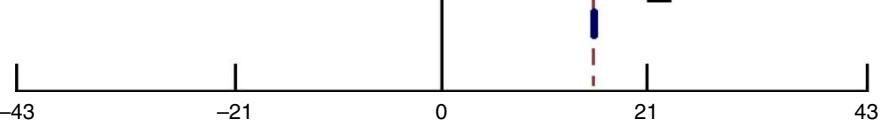

43

Favours treatment

Test for overall effect: $z=11.95, P<0.001$

Test for heterogeneity: $P<0.001, I^{2}=97.3 \%$

Favours control

Fig. 2. Effect of vitamin D supplementation on serum 25-hydroxyvitamin D.

was significant heterogeneity between studies (test for heterogeneity: $P<0.001$ and $I^{2}=97.3 \%$ ), we used the random-effects model to estimate the PMD in serum vitamin D concentration. Vitamin D supplementation resulted in a PMD of $15.52 \mathrm{ng} / \mathrm{ml}$ in serum 25(OH)D concentration (95\% CI 15.38, 15.67).
Meta-analysis for serum parathyroid hormone response

The PMD of serum PTH from the pre-trial was $-10 \cdot 17 \mathrm{pg} / \mathrm{ml}$ $(-11.83,-8.50$ to $+7.5 \mathrm{pg} / \mathrm{ml})$ in the intervention group. Individual and pooled MD in serum PTH concentration and $95 \% \mathrm{CI}$ 
Study ID

Chapuy MC 1987

Dawson-Hughes B 1991

Chapuy MC 1992

Chapuy MC 1992

Chapuy MC 1992

Ooms ME 1995

Dawson-Hughes B 1997

Dawson-Hughes B 1997

Krieg MA 1999

Krieg MA 1999

Hunter D 2000

Hunter D 2000

Pfeifer M 2001

Kenny AM 2003

Grados F 2003

Bischoff HA 2003

Brazier M 2005

Talwar SA 2007

Talwar SA 2007

Talwar SA 2007

Pittas AG 2007

Pittas AG 2007

Sneve M 2008

Sneve M 2008

Chel M 2008

Chel M 2008

Björkman M 2008

Björkman M 2008

Chel M 2008

Cashman KD 2008

Cashman KD 2008

Pfeifer M 2009

Pfeifer M 2009

Zitterman A 2009

Islam MZ 2010

Islam MZ 2010

Jorde R 2010

Jorde R 2010

Lips P 2010

Grimness G 2011

Chung HY 201

Sokol SI 2012

Ponda MP 2012

Harris SS 2012

Larsen T 2012

Kjærgaard M 2012

Salehpour A 2012

Goswami R 2012

Goswami R 2012

Overall

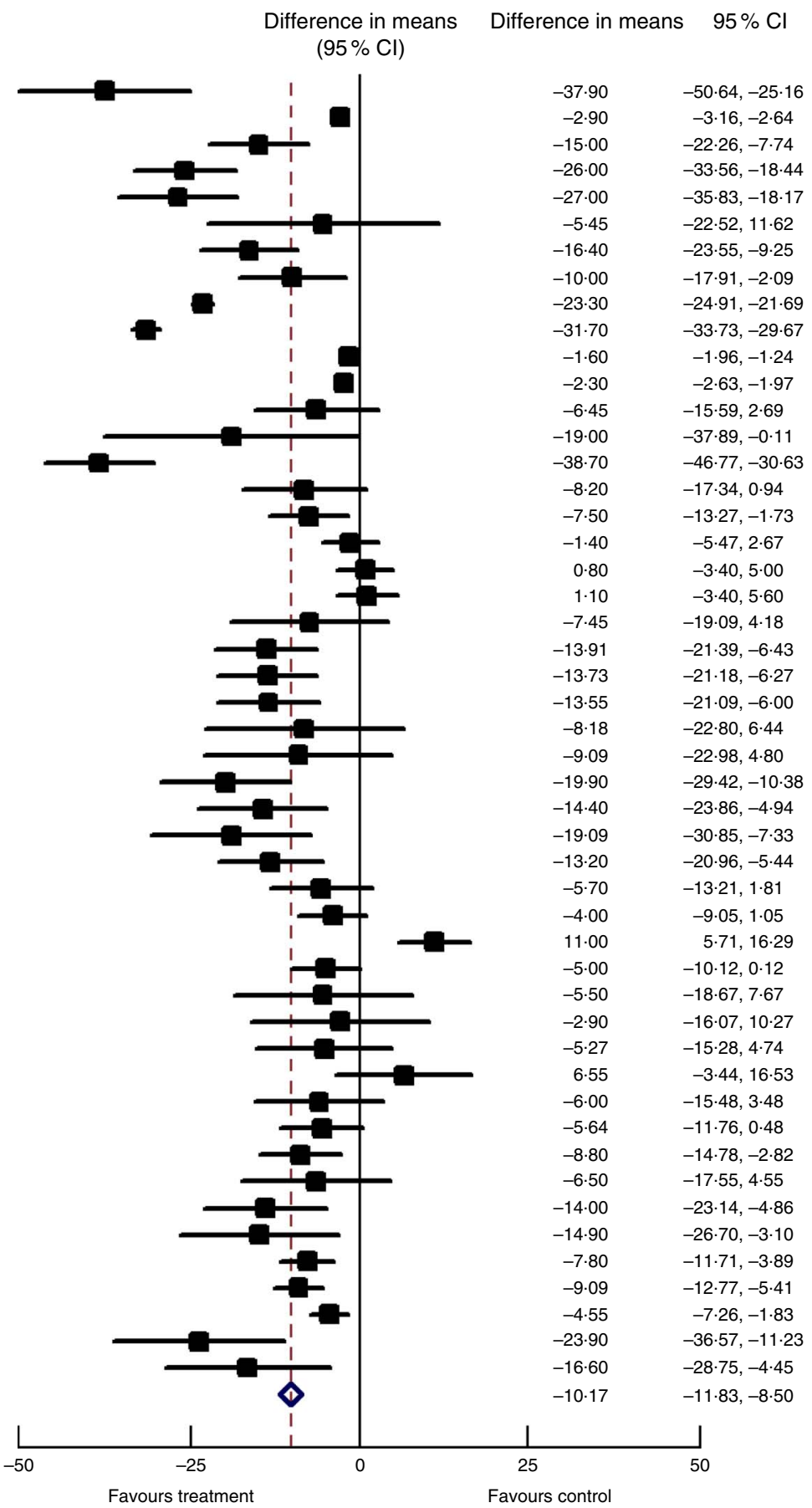

Favours treatment

Test for overall effect: $z=11.95, P<0.001$

Test for heterogeneity: $P<0.001, l^{2}=97.3 \%$

Fig. 3. Effect of vitamin D supplementation on serum parathyroid hormone (PTH)

after vitamin D supplementation that were derived from a random-effects model have been illustrated in Fig. 3. The meta-analysis demonstrated that the vitamin D supplementation decreased PTH levels significantly in the intervention group compared with the placebo (PMD: $-10 \cdot 17$; 95\% CI -11.84, -8.50). There was significant heterogeneity between studies (test for heterogeneity: $P<0.001$ ), and the $I^{2}$ value was $97.3 \%$, which can be interpreted as the amount of variation across the studies being attributed to heterogeneity rather than chance.

\section{Subgroup meta-analysis for serum parathyroid hormone response}

Each subgroup analyses significantly affected the treatment effect except for the dose of vitamin D supplementation (Table 2). 
Table 2. Subgroup analysis for effectiveness of vitamin D supplementation on serum parathyroid hormone (PTH) (Mean differences (MD) and $95 \%$ confidence intervals)

\begin{tabular}{|c|c|c|c|c|}
\hline Subgroups & Subtotal $(n)$ & MD & $95 \% \mathrm{Cl}$ & $P$ \\
\hline \multicolumn{4}{|l|}{ Vitamin D dose $(\mu \mathrm{g} / \mathrm{d})$} & 0.713 \\
\hline$\leq 20$ & 1173 & -2.98 & $-3 \cdot 24,-2 \cdot 72$ & \\
\hline$>20$ & 2559 & -3.05 & $-3 \cdot 28,-2 \cdot 81$ & \\
\hline \multicolumn{4}{|l|}{ Supplementation } & $<0.001$ \\
\hline Vitamin D & 1415 & -2.09 & $-2 \cdot 33,-1 \cdot 85$ & \\
\hline Vitamin D and Ca & 2317 & -4.08 & $-4 \cdot 33,-3 \cdot 82$ & \\
\hline \multicolumn{4}{|l|}{ Ca dose $(\mathrm{mg} / \mathrm{d})$} & $<0.001$ \\
\hline 0 & 1415 & -2.09 & $-2 \cdot 33,-1.85$ & \\
\hline $400-600$ & 1315 & -3.00 & $-3 \cdot 26,-2 \cdot 74$ & \\
\hline $600-1200$ & 1002 & $-22 \cdot 48$ & $-23.57,-21.40$ & \\
\hline \multicolumn{4}{|l|}{ Duration of trial (months) } & $<0.001$ \\
\hline$<3$ & 490 & $-2 \cdot 37$ & $-2 \cdot 69,-2 \cdot 04$ & \\
\hline $3-6$ & 1112 & -1.96 & $-2 \cdot 31,-1 \cdot 61$ & \\
\hline $6-12$ & 1228 & -3.52 & $-3.78,-3.26$ & \\
\hline$>12$ & 902 & $-18 \cdot 26$ & $-19.72,-16.79$ & \\
\hline \multicolumn{4}{|l|}{ Baseline serum 25(OH)D (ng/ml) } & $<0.001$ \\
\hline$<20$ & 2227 & $-16 \cdot 70$ & $-17 \cdot 75,-15 \cdot 84$ & \\
\hline$\geq 20$ & 1505 & -2.44 & $-2 \cdot 62,-2 \cdot 26$ & \\
\hline \multicolumn{5}{|l|}{ Baseline serum PTH $(\mathrm{pg} / \mathrm{ml})$} \\
\hline$\leq 6 \cdot 0$ & & & & $<0.001$ \\
\hline $6 \cdot 1-38 \cdot 0$ & 918 & $-6 \cdot 85$ & $-8.95,-5.11$ & \\
\hline $38.1-49.0$ & 1077 & -2.44 & $-2 \cdot 61,-2 \cdot 26$ & \\
\hline \multirow[t]{2}{*}{$\geq 49 \cdot 1$} & 882 & -17.49 & $-18.49,-16.49$ & \\
\hline & 855 & $-20 \cdot 67$ & $-23.34,-18.00$ & \\
\hline \multicolumn{4}{|l|}{ Age (years) } & $<0.001$ \\
\hline$\leq 50$ & 820 & -6.92 & $-8.74,-5.09$ & \\
\hline$>50$ & 2912 & -2.98 & $-3 \cdot 16,-2 \cdot 81$ & \\
\hline \multicolumn{4}{|l|}{ Participants' BMI (kg/m²) } & $<0.001$ \\
\hline \multicolumn{5}{|l|}{$<25.0$} \\
\hline $25 \cdot 0-30 \cdot 0$ & 476 & $-2 \cdot 01$ & $-2 \cdot 26,-1 \cdot 77$ & \\
\hline \multirow[t]{2}{*}{$\geq 30 \cdot 0$} & 1312 & $-18 \cdot 11$ & $-19.07,-17.15$ & \\
\hline & 511 & -5.86 & $-7.92,-3.80$ & \\
\hline \multicolumn{4}{|r|}{ 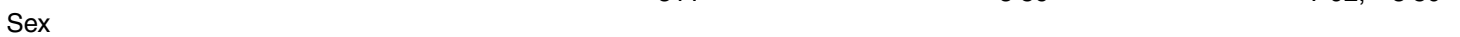 } & $<0.001$ \\
\hline Men-only studies & 179 & -11.34 & $-18.63,-4.05$ & \\
\hline Women-only studies & 1904 & -2.95 & $-3.13,-2.77$ & \\
\hline Men and women studies & 1649 & $-7 \cdot 20$ & $-8.65,-5.75$ & \\
\hline \multicolumn{4}{|l|}{ Study quality (Jadad score) } & $<0.001$ \\
\hline Low & 632 & $-25 \cdot 17$ & $-26 \cdot 34,-23.99$ & \\
\hline High & 3100 & -2.52 & $-2 \cdot 69,-2 \cdot 34$ & \\
\hline
\end{tabular}

25(OH)D, 25-hydroxyvitamin D.

There was a very small non-significant difference in PMD of serum PTH between vitamin D dosages of $\leq 20$ and $>20 \mu \mathrm{g} / \mathrm{d}$ $(-2.98(95 \%$ CI $-3 \cdot 24,-2 \cdot 72) v .-3 \cdot 05(95 \%$ CI $-3 \cdot 28,-2 \cdot 81))$ $(P=0 \cdot 713)$. The addition of $\mathrm{Ca}$ to vitamin $\mathrm{D}$ supplementation increased the treatment effect of vitamin $\mathrm{D}$ supplementation $(-4.08$ (95\% CI $-4.33,-3.82) v .-2.09$ (95\% CI -2.33, -1.85); $P<0.001)$. The treatment effect was also the best with Ca doses of $600-1200 \mathrm{mg} / \mathrm{d}$. Duration of vitamin D supplementation changed the treatment effect significantly, the best effect being observed when the trial duration was $>12$ months. Participants with low baseline $25(\mathrm{OH}) \mathrm{D}$ concentration $(25(\mathrm{OH}) \mathrm{D}<20 \mathrm{ng} / \mathrm{ml})$ had higher PMD of serum PTH than those whose serum $25(\mathrm{OH}) \mathrm{D}$ was $\geq 20 \mathrm{ng} / \mathrm{ml}(-16.70$ (95\% CI $-17.75,-15.84) v$. -2.44 (95\% CI $-2.62,-2 \cdot 26) ; \quad P<0.001)$. Baseline serum PTH also affected responses to vitamin D supplementation; participants with highest baseline serum PTH had the highest PMD. The treatment effect was lower in people aged $>50$ years than in those who were under $50(-2 \cdot 98(95 \% \mathrm{CI}-3 \cdot 16,-2 \cdot 81) v$. $-6.92(95 \%$ CI $-8.74,-5.09)) ; P<0.001)$. The treatment effect was the greatest in people with BMI ranging from 25 to
$30 \mathrm{~kg} / \mathrm{m}^{2}$ compared with those with BMI $<25 \mathrm{~kg} / \mathrm{m}^{2}(-18 \cdot 11$ (95\% CI -19.07, -17.15) v. -2.01 (95\% CI -2.26, -1.77)) and those with BMI $\geq 30 \mathrm{~kg} / \mathrm{m}^{2}(-18 \cdot 11(95 \% \mathrm{CI}-19 \cdot 07,-17 \cdot 15) v$. $-5.86(95 \%$ CI $-7.92,-3 \cdot 80) ; P<0.001)$. The treatment effect appeared to be greater in men-only studies compared with those conducted only in women $(-11.34$ (95\% CI $-18.63,-4 \cdot 05)$ v. $-2 \cdot 95$ (95\% CI $-3 \cdot 13,-2 \cdot 77) ; P<0.001)$.

\section{Meta-regression and source of heterogeneity for serum parathyroid hormone responses}

We used univariate meta-regression analysis to examine the variation in treatment effect attributed to some pre-specified covariates. The univariate meta-regression analysis showed that none of the covariates including the dose of vitamin D supplementation, dose of Ca supplementation, baseline serum PTH, age, duration of trial and baseline serum 25(OH)D concentrations have significant effects on between-study heterogeneity (Fig. 4 and Table 3). 
(a)

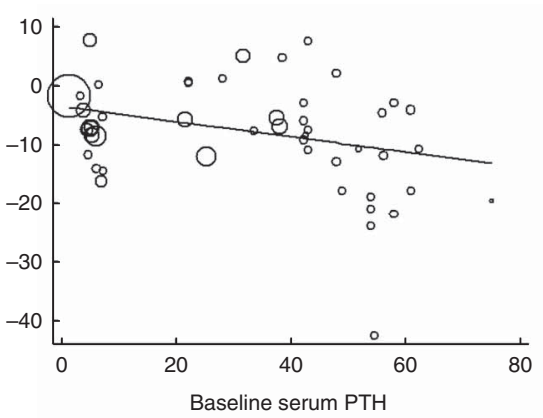

(c)

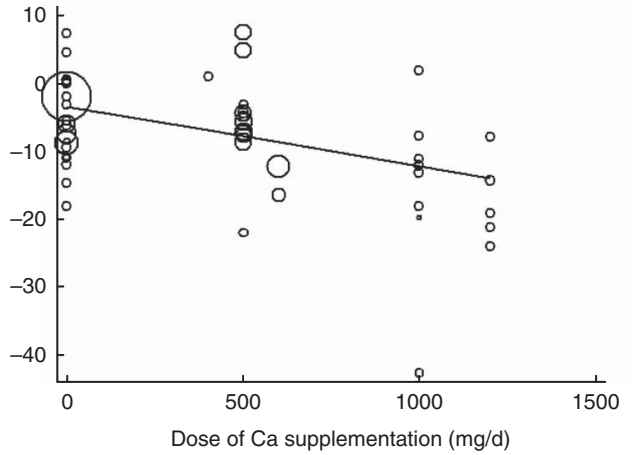

(b)

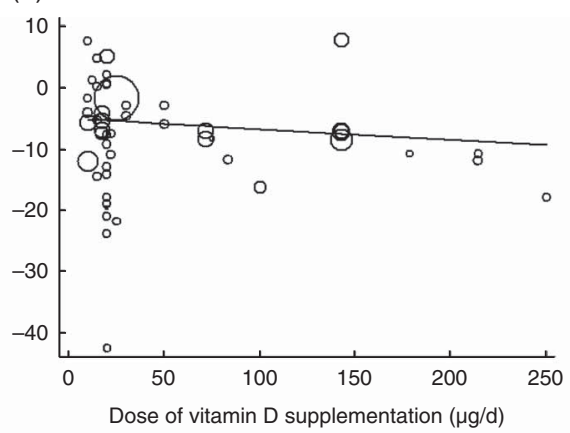

(d)

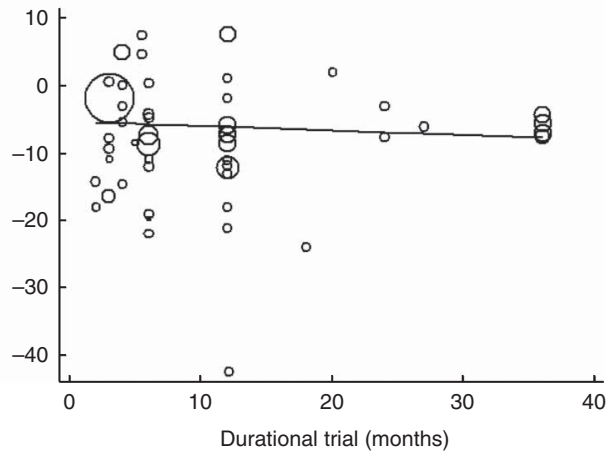

Fig. 4. Meta-regression analysis of baseline serum parathyroid hormone (PTH) (a), dose of vitamin D supplementation (b), dose of Ca supplementation (c) and trial duration (d).

Table 3. Summary of the meta-regression analysis (Slope and $95 \%$ confidence intervals)

\begin{tabular}{lccr}
\hline & Slope & $95 \% \mathrm{Cl}$ & $P$ \\
\hline Dose of vitamin D supplementation & -0.0004 & $-0.003,0.002$ & 0.686 \\
Dose of Ca supplementation & -0.009 & $-0.021,0.004$ & 0.170 \\
Baseline serum PTH concentrations & -0.129 & $-0.361,0.104$ & 0.272 \\
Age & -0.088 & $-0.333,0.158$ & 0.475 \\
Duration of trial & -0.067 & $-0.515,0.381$ & 0.765 \\
Baseline serum 25(OH)D & 0.229 & $-0.460,0.918$ & 0.507 \\
\hline
\end{tabular}

25(OH)D, 25-hydroxyvitamin D; PTH, parathyroid hormone.

\section{Ancillary analysis}

Using curve estimation regression models, we found non-linear associations between dose of vitamin D supplementation and WMD in the post-trial serum PTH concentrations. WMD in the post-trial PTH was negatively and quadratically correlated with the dose of vitamin D supplementation $\left(R^{2} 0 \cdot 03, P<0 \cdot 001\right.$; Fig. 5(a)), duration of the trial $\left(R^{2} 0.01, P<0.001\right.$; Fig. 5(b)) and $25(\mathrm{OH}) \mathrm{D}$ concentration $\left(R^{2} 0 \cdot 01, P<0 \cdot 001\right.$; Fig. $\left.5(\mathrm{c})\right)$, reaching a plateau following a dosage of $75 \mu \mathrm{g} / \mathrm{d}$ after 12 months and at baseline $25(\mathrm{OH}) \mathrm{D}$ of $30 \mathrm{ng} / \mathrm{ml}$.

\section{Cumulative and influence analysis}

No individual study was found to have excessive influence on the pooled effect when the influence analysis was carried out (Fig. 6). A cumulative random-effect meta-analysis showed consistency from the year 2000 (Fig. 7).

\section{Publication bias}

An asymmetric funnel plot suggested a possible publication bias (online Supplementary Fig. S1). Egger's linear regression also confirmed publication bias among studies $(P=0 \cdot 003)$, which is not unexpected because publication bias testing does not work when the meta-analysis has only selected RCT with a minimum of thirty participants. Publication bias, including funnel plot, assumes that all published studies are included and what is missing are the unpublished studies. However, the trim and fill method did not reveal any missing study, and thus the PMD estimate in post-trial PTH concentration remained unchanged.

\section{Discussion}

To our knowledge, this is the first meta-analysis of vitamin D supplementation on PTH response. In the present meta-analysis of forty-nine RCT arms, vitamin D supplementation significantly 
(a)

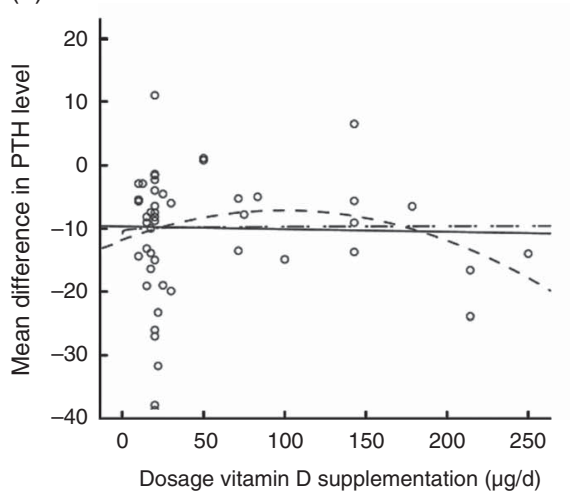

(b)

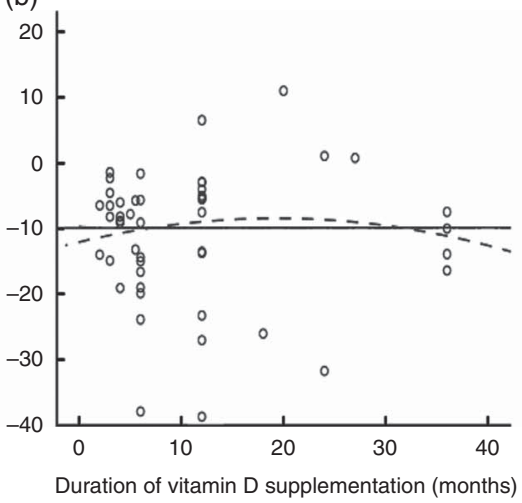

(c)

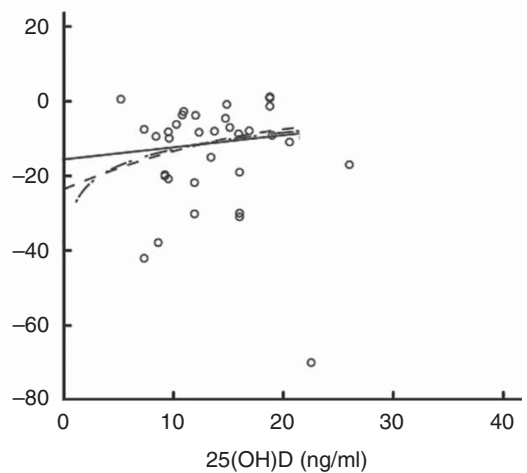

Fig. 5. Correlation of mean differences (MD) in parathyroid hormone (PTH) level with (a) dose of vitamin D, (b) duration of the trial and (c) baseline 25-hydroxyvitamin $\mathrm{D}(25(\mathrm{OH}) \mathrm{D})$. $\bigcirc$, Observed; - , Linear; - - - , Logarithmic; $-\ldots$, Quadratic.

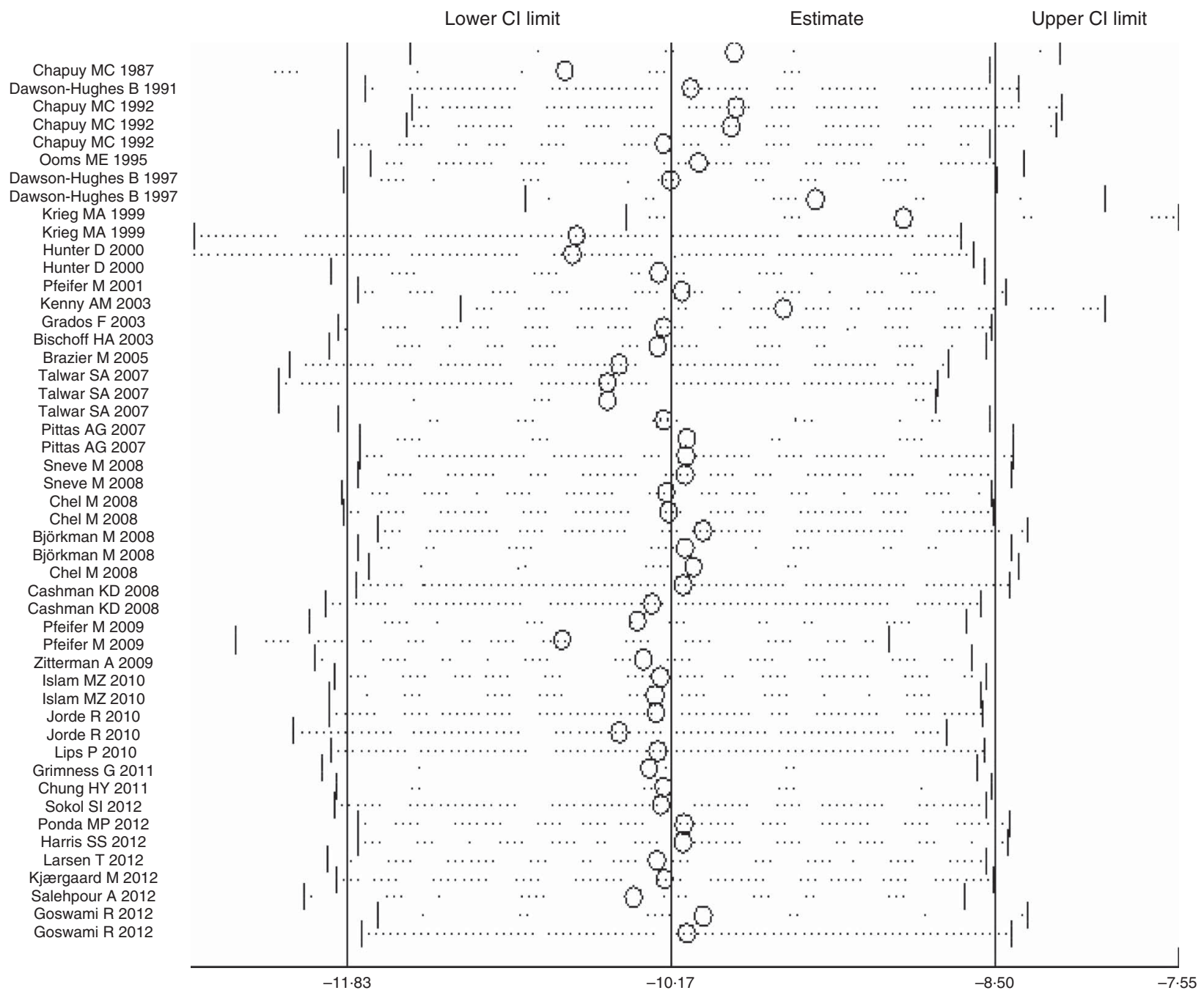

Fig. 6. Influence analysis.

increased serum 25(OH)D with a PMD of $15.5 \mathrm{ng} / \mathrm{dl}$. Moreover, vitamin D supplementation significantly reduced PTH concentration with PMD of $-10 \cdot 17 \mathrm{pg} / \mathrm{ml}(95 \% \mathrm{CI}-11 \cdot 83,-8.50$ to $+7.5 \mathrm{pg} / \mathrm{ml}$ ), although a significant heterogeneity was observed between studies, and this reduction depended on Ca dose, trial duration, baseline levels of PTH/25(OH)D, BMI, sex and age. The serum PTH reached a plateau after 12 months with a dose of vitamin $\mathrm{D}>75 \mu \mathrm{g} / \mathrm{d}$. 
Study ID

Chapuy MC 1987 Dawson-Hughes B 1991 Chapuy MC 1992 Chapuy MC 1992 Chapuy MC 1992 Ooms ME 1995 Dawson-Hughes B 1997 Dawson-Hughes B 1997 Krieg MA 1999 Krieg MA 1999 Hunter D 2000 Hunter D 2000 Pfeifer M 2001 Kenny AM 2003 Grados F 2003 Bischoff HA 2003 Brazier M 2005 Talwar SA 2007 Talwar SA 2007 Talwar SA 2007 Pittas AG 2007 Pittas AG 2007 Sneve M 2008 Sneve M 2008 Chel M 2008 Chel M 2008 Björkman M 2008 Björkman M 2008 Chel M 2008 Cashman KD 2008 Cashman KD 2008 Pfeifer M 2009 Pfeifer M 2009 Zitterman A 2009 Islam MZ 2010 Islam MZ 2010 Jorde R 2010 Jorde R 2010 Lips P 2010 Grimness G 2011 Chung HY 2011 Sokol SI 2012 Ponda MP 2012 Harris SS 2012 Larsen T 2012 Kjærgaard M 2012 Salehpour A 2012 Goswami R 2012 Goswami R 2012

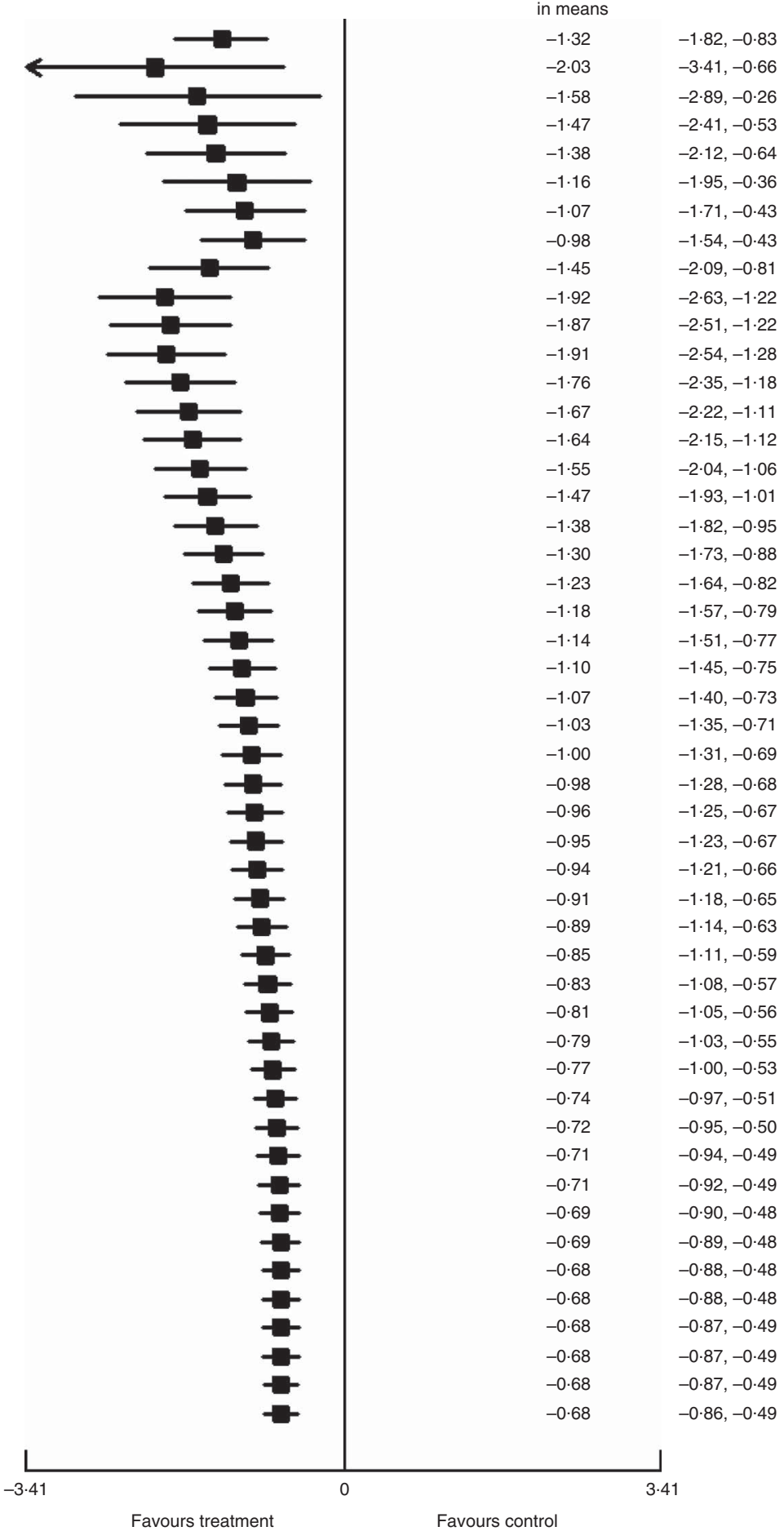

Fig. 7. Cumulative analysis.

\section{Dose of vitamin $D$}

In the present study, meta-regression analysis did not show the dose of vitamin D as a source of heterogeneity among studies. Vitamin D supplementation significantly decreased PTH concentrations in forty trials $31,38-41,44-46,48,49,51-55,57,59-70)$, thirty of which were in vitamin D-deficient populations ${ }^{(31,38,40-42,45,46,48,49,51-53,55,57,60,64-68,70,71)}$. It, however, increased PTH levels in eight trials ${ }^{(43,44,50,63,72,73)}$ and caused no changes in one trial ${ }^{(68)}$. Thirty of those trials with decrease in serum PTH used a vitamin D dose $\geq 20 \mu \mathrm{g} / \mathrm{d}$, and ten studies used vitamin D doses $>75 \mu \mathrm{g} / \mathrm{d}$. In those studies in which PTH 
responded to vitamin $\mathrm{D}$, the mean vitamin $\mathrm{D}$ supplementation was $57 \mu \mathrm{g} / \mathrm{d}$ and mean baseline $25(\mathrm{OH}) \mathrm{D}$ was $25.2 \mathrm{ng} / \mathrm{dl}$, whereas in those studies where PTH did not respond to vitamin D supplementation the mean dosage of vitamin D was $30.5 \mu \mathrm{g} / \mathrm{d}$ with baseline $25(\mathrm{OH}) \mathrm{D}$ level of $16.6 \mathrm{ng} / \mathrm{dl}$. Cranny et al. ${ }^{(74)}$ have found that vitamin $\mathrm{D}_{3}$ doses $\geq 17.5 \mu \mathrm{g}$ daily, significantly and consistently decreased serum concentrations of PTH in vitamin D-deficient populations. As Cranny et al. ${ }^{(74)}$ mentioned in their systematic review, reasons for lack of achievement of reduction in serum PTH in some studies may be due to a very low amount of the vitamin D dose for a population with low baseline $25(\mathrm{OH})$ D concentrations. In addition, changes in PTH level may not occur with baseline serum 25(OH)D above the threshold of PTH suppression $^{(74)}$.

PTH level plateaued in a quadratic model at a dose of vitamin $\mathrm{D}>75 \mu \mathrm{g} / \mathrm{d}$, a finding in contrast with the first dose-response RCT in older white women by Gallagher et $a l .{ }^{(75)}$, who found a linear relationship between vitamin $\mathrm{D}_{3}$ dose and PTH level. The quadratic dose term and interaction between quadratic dose and time were NS in the PTH model. Heaney et $a l .{ }^{(76)}$ reported that the $25(\mathrm{OH}) \mathrm{D}$ level that PTH will suppress is $75 \mathrm{nmol} / 1$. Interestingly, Vieth et al. reported that a dose above $82.5 \mu \mathrm{g}$ of ergocalciferol and $20 \mu \mathrm{g}$ of cholecalciferol was needed to ensure post-trial 25(OH)D levels of at least $50 \mathrm{nmol} / 1$, whereas to ensure mean post-trial $25(\mathrm{OH}) \mathrm{D}$ levels of at least $75 \mathrm{nmol} / \mathrm{l}$ doses of $12.5 \mu \mathrm{g} / \mathrm{d}$ and $71.25 \mu \mathrm{g} / \mathrm{d}$ are needed ${ }^{(8,77)}$. It was also reported that very high doses of vitamin D can certainly increase $25(\mathrm{OH}) \mathrm{D}$ to levels high enough to suppress PTH, but there are sparse data available on this. It is also interesting to note that it was estimated that intoxication may not occur with $25(\mathrm{OH}) \mathrm{D}$ levels up to $375 \mathrm{nmol} / \mathrm{l}^{(8,78)}$.

An earlier meta-analysis by Shab-Bidar et al. concluded that the treatment effect of oral vitamin $\mathrm{D}_{3}$ supplementation increases with increasing doses. Meta-regression results demonstrated a significant association between dose and serum 25(OH)D levels $(P=0.04)^{(5)}$, and the results were confirmed by Cranny ${ }^{(74)}$ who suggested that $2.5 \mu \mathrm{g}$ of vitamin $\mathrm{D}_{3}$ increases serum $25(\mathrm{OH}) \mathrm{D}$ concentrations by $1-2 \mathrm{nmol} / \mathrm{l}$, and therefore vitamin D supplements at doses of $10-20 \mu \mathrm{g}$ daily may be inadequate to prevent vitamin $\mathrm{D}$ deficiency in at-risk individuals $^{(74)}$

\section{Duration of trial}

Based on the findings of the present study, the best effect of treatment with vitamin D on PTH response was observed when the duration of the trial was $>12$ months. An increase in PMD was found, which plateaued after 12 months. Previous trials reported no significant change in PTH levels after 3 months of vitamin D supplementation $^{(5)}$, an observation, however, supported by Gallagher et $a l .{ }^{(75)}$, who also observed significant decreases in serum PTH levels with increasing vitamin D doses at 12 months.

\section{Calcium intake}

Serum PTH response may be partially modulated by the amount of $\mathrm{Ca}$ intake through diet or combined supplementation of vitamin $\mathrm{D}$ with $\mathrm{Ca}^{(79)}$. We noted a higher treatment effect in individuals with $\mathrm{Ca}$-vitamin $\mathrm{D}$ supplementation than in those who were supplemented only with vitamin D (-4.08 v. $-2 \cdot 09$; $P<0 \cdot 001)$. The treatment effect was also the best with Ca doses of $600-1200 \mathrm{mg} / \mathrm{d}$, which is important because PTH suppression may not be ensured without sufficient $\mathrm{Ca}$ intakes, especially when there are several reports in which inadequate dietary $\mathrm{Ca}$ is prevalent throughout the world. In contrast, data from another study suggest that vitamin D sufficiency can ensure ideal serum PTH values even when the $\mathrm{Ca}$ intake level is $<800 \mathrm{mg} / \mathrm{d}$, whereas high $\mathrm{Ca}$ intake $(>1200 \mathrm{mg} / \mathrm{d})$ is not sufficient to maintain ideal serum PTH, as long as the vitamin D status is insufficient ${ }^{(80)}$. This is further reflected in ionised $\mathrm{Ca}$ levels that were dependent on serum 25(OH)D levels but not on Ca intake.

Another study concluded that vitamin D supplementation had a reducing effect on serum PTH only when the vitamin D per se was given ${ }^{(81)}$. Although sufficient intakes of vitamin $\mathrm{D}$ and $\mathrm{Ca}$ are definitely important, $\mathrm{Ca}$ intake may not necessarily be a contributing factor in maintaining Ca homoeostasis as long as vitamin D status would be benefitted with vitamin D supplementation and sun exposure ${ }^{(82)}$. Other investigators have suggested that the response of circulating $25(\mathrm{OH}) \mathrm{D}$ to supplemental vitamin D was similar whether Ca was co-administered or not ${ }^{(83)}$. Aloia et $a l .{ }^{(84)}$ reported that most of the studies examining optimal vitamin D status do not control for Ca intake, and they found that serum $25(\mathrm{OH}) \mathrm{D}$ and dietary $\mathrm{Ca}$ influence the PTH threshold independently and together account for about $67 \%$ of the variance in reported thresholds among the studies. The contribution of dietary $\mathrm{Ca}$ to the prediction of the threshold remained significant even after controlling for serum $25(\mathrm{OH}) \mathrm{D}^{(84)}$.

One study suggested that the response of serum PTH differs by $\mathrm{Ca}$ intake, only in those individuals with low vitamin $\mathrm{D}$ status, which can be explained by the less-active transport of $\mathrm{Ca}^{(80)}$. It has been suggested that in the absence of sufficient active Ca transport in the gut, as in vitamin D insufficiency, one must meet the requirements of the body with higher $\mathrm{Ca}$ intakes $^{(85)}$

We explored the interaction between baseline $25(\mathrm{OH}) \mathrm{D}$ and Ca intake, and found that in studies with $25(\mathrm{OH}) \mathrm{D}>50 \mathrm{nmol} / \mathrm{l} \mathrm{Ca}$ intake did not affect PTH response, whereas in those with a mean $25(\mathrm{OH}) \mathrm{D}<50 \mathrm{nmol} / \mathrm{l}$ dietary $\mathrm{Ca}$ was inversely related to PTH (data not shown). These results are in agreement with those of Aloia et al ${ }^{(84)}$ following a study of African-Americans.

Some studies have discussed the sparing effect of dietary $\mathrm{Ca}$ intake on serum 25(OH)D because PTH concentrations are suppressed, thus less serum $25(\mathrm{OH}) \mathrm{D}$ is converted to $1,25(\mathrm{OH}) \mathrm{D}^{(86)}$.

\section{Baseline 25-hydroxyvitamin D concentration}

In this study, participants with low baseline 25(OH)D concentration $(25(\mathrm{OH}) \mathrm{D}<20 \mathrm{ng} / \mathrm{ml})$ had more reduction in serum PTH than those in whom serum $25(\mathrm{OH}) \mathrm{D}$ was $\geq 20 \mathrm{ng} / \mathrm{ml}$ $(-16.70 v .-2 \cdot 44 ; P<0 \cdot 001)$. According to our previous study, baseline $25(\mathrm{OH}) \mathrm{D}$ was one of the important determinants of response to vitamin D supplementation ${ }^{(5)}$. In the present study, 
we categorised both vitamin D deficiency and insufficiency together. Vitamin D deficiency is known to be associated with secondary hyperparathyroidism, increased bone turnover and bone loss ${ }^{(87)}$. A negative correlation between serum PTH and serum $25(\mathrm{OH}) \mathrm{D}$ levels has been reported by many investigators $^{(79)}$. We expect that betterment of vitamin D deficiency would follow after significant improvements of PTH concentration.

Some have argued that serum PTH declines significantly after vitamin $\mathrm{D}$ and $\mathrm{Ca}$ intervention is initiated with low baseline serum $25(\mathrm{OH})$ D levels $<20 \mathrm{ng} / \mathrm{ml}(<50 \mathrm{nmol} / \mathrm{l})^{(74)}$. Interestingly, Lips et al. ${ }^{(79)}$ demonstrated that the mean serum PTH level was $30 \%$ higher in those with low serum 25(OH)D $(<25 \mathrm{nmol} / \mathrm{l})$ than in women with higher serum 25(OH)D $(<50 \mathrm{nmol} / \mathrm{l})$. Based on the findings of the Gallagher et al. ${ }^{(88)}$ study, clinical importance was only observed in $25(\mathrm{OH}) \mathrm{D}$-deficient status and elevated PTH level. However, the threshold of 25(OH)D to prevent a rise in PTH concentration varies widely, as many studies have found most estimates clustered between 40 and $50 \mathrm{nmol} / \mathrm{l}$ or between 70 and $80 \mathrm{nmol} / \mathrm{l}$. The variability in the estimates may be due to different $\mathrm{Ca}$ intakes, different $25(\mathrm{OH}) \mathrm{D}$ assays, age of the participants and vitamin $\mathrm{D}$ insufficiency $^{(84)}$.

In the meta-regression analysis, we found a non-significant association between baseline 25(OH)D and response of PTH. Aloia et $a l .{ }^{(84)}$ in a review of twenty-five studies reported that the average correlation between PTH and vitamin D was $-0 \cdot 30$ and serum 25(OH)D just contains $9 \%$ of the variance in PTH.

\section{Age}

The treatment effect was lower in people aged $>50$ years than in those who were younger than $50(-2.98 v$. -6.92$) ; P<0.001)$. Previous observations have demonstrated that older participants had a better response to vitamin $\mathrm{D}_{3}$ intake, although the response was independent of baseline $25(\mathrm{OH}) \mathrm{D}^{(5)}$. Bjorkman et al. also showed that age of the patients can have major effects on the elevation of PTH levels independently. The higher effect could be attributed to the high prevalence of vitamin D deficiency in the elderly ${ }^{(89,90)}$. We expected that following amelioration of vitamin D deficiency PTH level might be suppressed maximally. However, the better response to vitamin D intake was not enough to guarantee PTH suppression in the elderly, as the achieved $25(\mathrm{OH}) \mathrm{D}$ was not sufficient. Indeed, skin content of 7-dehydrocholesterol drops by $50 \%$ between $20-80$ years of age ${ }^{(91)}$, and the same dose of UV-B radiation in older individuals produces a smaller rise in serum $25(\mathrm{OH}) \mathrm{D}$ compared with young individuals ${ }^{(92)}$. Ageing is associated with a decline in renal function, and higher concentrations of $25(\mathrm{OH}) \mathrm{D}$ are needed to prevent a rise in serum PTH in the elderly ${ }^{(93)}$.

\section{$B M I$}

In the present study, the treatment effect was the highest in people who were overweight and obese. There is an altered vitamin D endocrine system in obese individuals ${ }^{(94)}$. Studies have shown that obesity, and specifically body fat content, is inversely associated with $25(\mathrm{OH}) \mathrm{D}$ and is positively associated with PTH concentrations ${ }^{(95,96)}$. In a recent study by Gallagher et $a l .{ }^{(75)}$, underweight to normal weight and the overweight groups tended to have lower PTH levels than the obese group $(P=0.065)$. It has been reported that, with a similar amount of 7 -dehydrocholesterol in the epidermis, the increase in serum $25(\mathrm{OH}) \mathrm{D}$ after UV-B irradiation was $57 \%$ less in obese compared with non-obese subjects ${ }^{(97)}$. It is suggested that lower serum $25(\mathrm{OH}) \mathrm{D}$ may be a factor partially contributing to the relationship of higher serum PTH with greater adiposity ${ }^{(95,96,98)}$. In a recent study, Shapses et al. showed that PTH is suppressed at a lower $25(\mathrm{OH}) \mathrm{D}$ concentration in the obese compared with the entire population. Therefore, the lower average $25(\mathrm{OH}) \mathrm{D}$ concentrations in the obese may not have the same physiological significance as in the general population. Evidence also shows that, in spite of physiological changes associated with the higher BMI, including higher PTH levels and higher bone resorption, bone mineral density may not be reduced in overweight women ${ }^{(99)}$.

\section{Limitations}

This meta-analysis has some limitations. First, many analyses suffer from high levels of heterogeneity, but this is not unexpected because the included RCT had variable population groups, doses and supplementation forms (vitamin $\mathrm{D}_{2}$ or $\mathrm{D}_{3}$, with or without supplemental $\mathrm{Ca}$ ). Second, our search was limited to the published studies. Third, not all studies reported data for seasonal influences, sun exposure, physical activity and dietary intake of vitamin $\mathrm{D}$ and $\mathrm{Ca}$; therefore, we were unable to adjust for these variables in our analysis. Fourth, multiple comparisons in the subgroup analysis may increase the likelihood of type 1 error. Finally, the validity of the study results may be influenced by the use of different assay types.

\section{Conclusion}

In conclusion, although the present meta-analysis was hindered by some limitations, all of which contributed to the heterogeneity, it provides some interesting evidence, suggesting that suppression of PTH level needs higher vitamin D intake $(75 \mu \mathrm{g} / \mathrm{d})$ and longer duration (12 months) than those currently recommended, which should be taken into account for nutritional recommendations.

\section{Acknowledgements}

The authors thank ERC for their financial support.

S. S.-B. designed and supervised the study (project conception, development of overall research plan and study oversight). S. S.-B and N. M. conducted the research (hands-on conduct of the experiments and data collection), performed most of statistical analysis and wrote the preliminary manuscript. P. M., F. H. and F. A. helped intellectually in finalising the manuscript. All the authors read and approved the final version of the manuscript.

There are no conflicts of interest to declare. 


\section{Supplementary material}

For supplementary material/s referred to in this article, please visit http://dx.doi.org/doi:10.1017/S0007114515003189

\section{References}

1. Holick MF (2007) Vitamin D deficiency. New Engl J Med 357 , 266-281.

2. Dawson-Hughes B, Heaney RP, Holick MF, et al. (2005) Estimates of optimal vitamin D status. Osteoporos Int 16, 713716.

3. Bouillon R, Van Schoor NM, Gielen E, et al. (2013) Optimal vitamin D status: a critical analysis on the basis of evidencebased medicine. J Clin Endocrinol Metab 98, E1283-E1304.

4. Aloia JF (2011) The 2011 report on dietary reference intake for vitamin D: where do we go from here? I Clin Endocrinol Metab 96, 2987-2996.

5. Shab-Bidar S, Bours S, Geusens PP, et al. (2014) Serum $25(\mathrm{OH}) \mathrm{D}$ response to vitamin $\mathrm{D}_{3}$ supplementation: a metaregression analysis Nutrition 30, 975-985.

6. Bates C, Carter G, Mishra G, et al. (2003) In a population study, can parathyroid hormone aid the definition of adequate vitamin D status? A study of people aged 65 years and over from the British National Diet and Nutrition Survey. Osteoporos Int 14, 152-159.

7. Sai A, Walters R, Fang X, et al. (2010) Relationship between vitamin D, parathyroid hormone, and bone health. Clin Endocrinol Metab 96, E436-E446.

8. Björkman M, Sorva A \& Tilvis R (2009) Responses of parathyroid hormone to vitamin D supplementation: a systematic review of clinical trials. Arch Gerontol Geriatr $\mathbf{4 8}$ 160-166.

9. Moher D, Liberati A, Tetzlaff J, et al. (2009) Preferred reporting items for systematic reviews and meta-analyses: the PRISMA statement. Ann Int Med 151, 264-269.

10. Richter B \& Berger M (2000) Randomized controlled trials remain fundamental to clinical decision making in type II diabetes mellitus: a comment to the debate on randomized controlled trials. Diabetologia. 43, 254-258.

11. Ross AC, Taylor CL, Yaktine AL, et al. (editors) (2011) Committee to Review Dietary Reference Intakes for Vitamin D and Calcium. Washington, DC: National Academies Press.

12. Trang HM, Cole D, Rubin LA, et al. (1998) Evidence that vitamin $\mathrm{D}_{3}$ increases serum 25-hydroxyvitamin $\mathrm{D}$ more efficiently than does vitamin $\mathrm{D}_{2}$. Am J Clin Nutr 68, 854-858.

13. Armas LA, Hollis BW \& Heaney RP (2004) Vitamin $\mathrm{D}_{2}$ is much less effective than vitamin $\mathrm{D}_{3}$ in humans. I Clin Endocrinol Metab 89, 5387-5391.

14. Harris SS \& Dawson-Hughes B (2002) Plasma vitamin D and 25OHD responses of young and old men to supplementation with vitamin $\mathrm{D}_{3}$. J Am Coll Nutr 21, 357-362.

15. Viljakainen HT, Palssa A, Karkkainen M, et al. (2006) How much vitamin $\mathrm{D}_{3}$ do the elderly need? J Am Coll Nutr 25, 429-435.

16. Moher D, Klassen TP, Schulz KF, et al. (2000) What contributions do languages other than English make on the results of meta-analyses? J Clin Epidemiol 53, 964-972.

17. Jüni P, Holenstein F, Sterne J, et al. (2002) Direction and impact of language bias in meta-analyses of controlled trials: empirical study Int J Epidemiol 31, 115-123.

18. Steinberg K, Smith S, Stroup D, et al. (1997) Comparison of effect estimates from a meta-analysis of summary data from published studies and from a meta-analysis using individual patient data for ovarian cancer studies. Am J Epidemiol 145 917-925.
19. Jadad AR, Moore RA, Carroll D, et al. (1996) Assessing the quality of reports of randomized clinical trials: is blinding necessary? Control Clin Trials. 17, 1-12.

20. Cochran W (1954) The combination of estimates from different experiments. Biometrics 8, 101-129.

21. DerSimonian R \& Laird N (1986) Meta-analysis in clinical trials. Control Clin Trials 7, 177-188.

22. Lau J, Antman EM, Jimenez-Silva J, et al. (1992) Cumulative meta-analysis of therapeutic trials for myocardial infarction. $N$ Engl J Med 327, 248-254.

23. Egger M, Davey Smith G, Schneider M, et al. (1997) Bias in meta-analysis detected by a simple, graphical test. BMJ 315, 629-634.

24. Duval S \& Tweedie R (2000) Trim and fill: a simple funnelplot-based method of testing and adjusting for publication bias in meta-analysis. Biometrics 56, 455-463.

25. Suzuki M, Yoshioka M, Hashimoto M, et al. (2013) Randomized, double-blind, placebo-controlled trial of vitamin D supplementation in Parkinson disease. Am J Clin Nutr 97, 1004-1013.

26. Chapuy MC, Chapuy P \& Meunier PJ (1987) Calcium and vitamin D supplements: effects on calcium metabolism in elderly people. Am J Clin Nutr 46, 324-328.

27. Dawson-Hughes B, Dallal GE, Krall EA, et al. (1991) Effect of vitamin $\mathrm{D}$ supplementation on wintertime and overall bone loss in healthy postmenopausal women. Ann Intern Med $\mathbf{1 1 5}$, 505-512

28. Chapuy MC, Arlot ME, Duboeuf F, et al. (1992) Vitamin $\mathrm{D}_{3}$ and calcium to prevent hip fractures in the elderly women. $N$ Engl J Med 327, 1637-1642.

29. Ooms ME, Roos JC, Bezemer PD, et al. (1995) Prevention of bone loss by vitamin D supplementation in elderly women: a randomized double-blind trial. J Clin Endocrinol Metab 80, 1052-1058.

30. Dawson-Hughes B, Harris SS, Krall EA, et al. (1997) Effect of calcium and vitamin D supplementation on bone density in men and women 65 years of age or older. N Engl J Med 337, 670-676.

31. Krieg M, Jacquet A, Bremgartner M, et al. (1999) Effect of supplementation with vitamin $\mathrm{D}_{3}$ and calcium on quantitative ultrasound of bone in elderly institutionalized women: a longitudinal study. Osteoporos Int 9, 483-488.

32. Hunter D, Major P, Arden N, et al. (2000) A randomized controlled trial of vitamin D supplementation on preventing postmenopausal bone loss and modifying bone metabolism using identical twin pairs. J Bone Miner Res 15, 2276-2283.

33. Pfeifer M, Begerow B, Minne HW, et al. (2001) Effects of a short-term vitamin $\mathrm{D}(3)$ and calcium supplementation on blood pressure and parathyroid hormone levels in elderly women. J Clin Endocrinol Metab 86, 1633-1637.

34. Kenny AM, Biskup B, Robbins B, et al. (2003) Effects of vitamin D supplementation on strength, physical function, and health perception in older, community-dwelling men. $J \mathrm{Am}$ Geriatr SOC 51, 1762-1767.

35. Grados F, Brazier M, Kamel S, et al. (2003) Prediction of bone mass density variation by bone remodeling markers in postmenopausal women with vitamin D insufficiency treated with calcium and vitamin D supplementation. J Clin Endocrinol Metab 88, 5175-5179.

36. Bischoff HA, Stahelin HB, Dick W, et al. (2003) Effects of vitamin $\mathrm{D}$ and calcium supplementation on falls: a randomized controlled trial. J Bone Miner Res 18, 343-351.

37. Brazier M, Grados F, Kamel S, et al. (2005) Clinical and laboratory safety of one year's use of a combination calcium + vitamin $\mathrm{D}$ tablet in ambulatory elderly women with vitamin D insufficiency: results of a multicenter, randomized, double-blind, placebo-controlled study. Clin Ther 27, 1885-1893. 
38. Talwar SA, Aloia JF, Pollack S, et al. (2007) Dose response to vitamin D supplementation among postmenopausal African American women. Am J Clin Nutr 86, 1657-1662.

39. Pittas AG, Harris SS, Stark PC, et al. (2007) The effects of calcium and vitamin D supplementation on blood glucose and markers of inflammation in nondiabetic adults. Diabetes Care 30, 980-986.

40. Sneve M, Figenschau Y \& Jorde R (2008) Supplementation with cholecalciferol does not result in weight reduction in overweight and obese subjects. Eur J Endocrinol 159, 675-684.

41. Chel V, Wijnhoven HA, Smit JH, et al. (2008) Efficacy of different doses and time intervals of oral vitamin D supplementation with or without calcium in elderly nursing home residents. Osteoporos Int 19, 663-671.

42. Bjorkman M, Sorva A, Risteli J, et al. (2008) Vitamin D supplementation has minor effects on parathyroid hormone and bone turnover markers in vitamin D-deficient bedridden older patients. Age Ageing 37, 25-31.

43. Cashman KD, Hill TR, Lucey AJ, et al. (2008) Estimation of the dietary requirement for vitamin $\mathrm{D}$ in healthy adults. Am J Clin Nutr 88, 1535-1542.

44. Pfeifer M, Begerow B, Minne HW, et al. (2009) Effects of a long-term vitamin $\mathrm{D}$ and calcium supplementation on falls and parameters of muscle function in community-dwelling older individuals. Osteoporos Int 20, 315-322.

45. Zittermann A, Frisch S, Berthold HK, et al. (2009) Vitamin D supplementation enhances the beneficial effects of weight loss on cardiovascular disease risk markers. Am J Clin Nutr 89, 1321-1327.

46. Islam MZ, Shamim AA, Viljakainen HT, et al. (2010) Effect of vitamin $\mathrm{D}$, calcium and multiple micronutrient supplementation on vitamin D and bone status in Bangladeshi premenopausal garment factory workers with hypovitaminosis D: a doubleblinded, randomised, placebo-controlled 1-year intervention. Br J Nutr 104, 241-247.

47. Jorde R, Sneve M, Torjesen P, et al. (2010) Parameters of the thrombogram are associated with serum 25-hydroxyvitamin D levels at baseline, but not affected during supplementation with vitamin D. Thromb Res 125, e210-e213.

48. Lips P, Binkley N, Pfeifer M, et al. (2010) Once-weekly dose of 8400 IU vitamin $\mathrm{D}(3)$ compared with placebo: effects on neuromuscular function and tolerability in older adults with vitamin D insufficiency. Am J Clin Nutr 91, 985-991.

49. Grimnes G, Figenschau Y, Almas B, et al. (2011) Vitamin D, insulin secretion, sensitivity, and lipids: results from a case-control study and a randomized controlled trial using hyperglycemic clamp technique. Diabetes 60, 2748-2757.

50. Chung HY, Chin SO, Kang MI, et al. (2011) Efficacy of risedronate with cholecalciferol on 25-hydroxyvitamin D level and bone turnover in Korean patients with osteoporosis. Clin Endocrinol (Oxf) 74, 699-704.

51. Sokol SI, Srinivas V, Crandall JP, et al. (2012) The effects of vitamin D repletion on endothelial function and inflammation in patients with coronary artery disease. Vasc Med 17, 394-404.

52. Ponda MP, Dowd K, Finkielstein D, et al. (2012) The short-term effects of vitamin D repletion on cholesterol: a randomized, placebo-controlled trial. Arterioscler Thromb Vasc Biol 32, 2510-2515.

53. Harris SS, Pittas AG \& Palermo NJ (2012) A randomized, placebo-controlled trial of vitamin D supplementation to improve glycaemia in overweight and obese African Americans. Diabetes Obes Metab 14, 789-794.

54. Larsen T, Mose FH, Bech JN, et al. (2012) Effect of cholecalciferol supplementation during winter months in patients with hypertension: a randomized, placebo-controlled trial. $A m J$ Hypertens 25, 1215-1222.
55. Kjaergaard M, Waterloo K, Wang CE, et al. (2012) Effect of vitamin D supplement on depression scores in people with low levels of serum 25-hydroxyvitamin D: nested case-control study and randomised clinical trial. Br J Psychiatry 201, 360-368.

56. Salehpour A, Hosseinpanah F, Shidfar F, et al. (2012) A 12-week double-blind randomized clinical trial of vitamin D (3) supplementation on body fat mass in healthy overweight and obese women. Nutr J 11, 78.

57. Goswami R, Vatsa M, Sreenivas V, et al. (2012) Skeletal muscle strength in young Asian Indian females after vitamin D and calcium supplementation: a double-blind randomized controlled clinical trial. J Clin Endocrinol Metab 97, 4709-4716.

58. Suzuki M, Yoshioka M, Hashimoto M, et al. (2013) Randomized, double-blind, placebo-controlled trial of vitamin D supplementation in Parkinson disease. Am J Clin Nutr 97, 1004-1013

59. Ooms ME, Lips P, Roos JC, et al. (1995) Vitamin D status and sex hormone binding globulin: determinants of bone turnover and bone mineral density in elderly women.J Bone Miner Res 10, 1177-1184.

60. Salehpour A, Hosseinpanah F, Shidfar F, et al. (2012) A 12-week double-blind randomized clinical trial of vitamin $\mathrm{D}_{3}$ supplementation on body fat mass in healthy overweight and obese women. Nutr J 11, 78.

61. Bjorkman M, Sorva A \& Tilvis R (2008) Vitamin D supplementation has no major effect on pain or pain behavior in bedridden geriatric patients with advanced dementia. Aging Clin Exp Res 20, 316-321.

62. Dawson-Hughes B, Harris SS, Krall EA, et al. (1997) Effect of calcium and vitamin $\mathrm{D}$ supplementation on bone density in men and women 65 years of age or older. New Engl J Med 337, 670-676.

63. Jorde R, Sneve M, Torjesen PA, et al. (2010) No effect of supplementation with cholecalciferol on cytokines and markers of inflammation in overweight and obese subjects. Cytokine 50, 175-180.

64. Bischoff HA, Stähelin HB, Dick W, et al. (2003) Effects of vitamin $D$ and calcium supplementation on falls: a randomized controlled trial. J Bone Miner Res 8, 343-351.

65. Pfeifer M, Begerow B, Minne HW, et al. (2001) Effects of a short-term vitamin $\mathrm{D}_{3}$ and calcium supplementation on blood pressure and parathyroid hormone levels in elderly women 1. J Clin Endocrinol Metab 86, 1633-1637.

66. Brazier M, Grados F, Kamel S, et al. (2005) Clinical and laboratory safety of one year's use of a combination calcium + vitamin D tablet in ambulatory elderly women with vitamin $\mathrm{D}$ insufficiency: results of a mlticenter, randomized, double-blind, placebo-controlled study. Clin Ther $\mathbf{2 7}$, $1885-1893$

67. Chapuy M, Chapuy P \& Meunier P (1987) Calcium and vitamin D supplements: effects on calcium metabolism in elderly people. Am J Clin Nutr 46, 324-328.

68. Chapuy MC, Arlot ME, Duboeuf F, et al. (1992) Vitamin $\mathrm{D}_{3}$ and calcium to prevent hip fractures in elderly women. New Engl J Med 327, 1637-1642.

69. Kenny AM, Biskup B, Robbins B, et al. (2003) Effects of vitamin D supplementation on strength, physical function, and health perception in older, community-dwelling men. $J \mathrm{Am}$ Geriatr Soc 51, 1762-1767.

70. Grados F, Brazier M, Kamel S, et al. (2003) Prediction of bone mass density variation by bone remodeling markers in postmenopausal women with vitamin D insufficiency treated with calcium and vitamin D supplementation. J Clin Endocrinol Metab 88, 5175-5179. 
71. Ooms ME, Roos J, Bezemer PD, et al. (1995) Prevention of bone loss by vitamin D supplementation in elderly women: a randomized double-blind trial. J Clin Endocrinol Metab 80, 1052-1058.

72. Dawson-Hughes B, Dallal GE, Krall EA, et al. (1991) Effect of vitamin $\mathrm{D}$ supplementation on wintertime and overall bone loss in healthy postmenopausal women. Ann Int Med 115, 505-512.

73. Hunter D, Major P, Arden N, et al. (2000) A randomized controlled trial of vitamin $\mathrm{D}$ supplementation on preventing postmenopausal bone loss and modifying bone metabolism using identical twin pairs. J Bone Min Res 15, 2276-2283.

74. Cranney A, Horsley T, O'Donnell S, et al. (2007) Effectiveness and safety of vitamin D in relation to bone health. Evid Rep Technol Assess (Full Rep) 158, 1-235.

75. Gallagher JC, Sai A, Templin T, et al. (2012) Dose response to vitamin D supplementation in postmenopausal women: a randomized trial. Ann Int Med 156, 425-437.

76. Heaney RP, Davies KM, Chen TC, et al. (2003) Human serum 25-hydroxycholecalciferol response to extended oral dosing with cholecalciferol. Am J Clin Nutr 77, 204-210.

77. Vieth R, Bischoff-Ferrari H, Boucher BJ, et al. (2007) The urgent need to recommend an intake of vitamin $\mathrm{D}$ that is effective. Am J Clin Nutr 85, 649-650.

78. Holick MF (2006) The role of vitamin D for bone health and fracture prevention. Curr Osteoporos Rep 4, 96-102.

79. Lips P, Duong T, Oleksik A, et al. (2001) A global study of vitamin D status and parathyroid function in postmenopausal women with osteoporosis: baseline data from the multiple outcomes of raloxifene evaluation clinical trial. J Clin Endocrinol Metab 86, 1212-1221.

80. Steingrimsdottir L, Gunnarsson O, Indridason OS, et al. (2005) Relationship between serum parathyroid hormone levels, vitamin D sufficiency, and calcium intake. JAMA 294, 2336-2341.

81. Seamans KM \& Cashman KD (2009) Existing and potentially novel functional markers of vitamin D status: a systematic review. Am J Clin Nutr 89, 1997S-2008S.

82. Baron J, Beach MF, Mandel J, et al. (1999) Calcium supplements for the prevention of colorectal adenomas. New Engl J Med 340, 101-107.

83. Weaver CM \& Fleet JC (2004) Vitamin D requirements: current and future. Am J Clin Nutr 80, 1735S-1739S.

84. Aloia JF, Talwar SA, Pollack S, et al. (2006) Optimal vitamin D status and serum parathyroid hormone concentrations in African American women. Am J Clin Nutr 84, 602-609.

85. Heaney R \& Feldman D (1997) Vitamin D: role in the calcium economy. In Vitamin D, pp. 485-497. San Diego, CA: Academic Press.
86. Lips P (2004) Which circulating level of 25-hydroxyvitamin D is appropriate? J Steroid Biochem Mol Biol 89, 611-614.

87. Lips P (2001) Vitamin D deficiency and secondary hyperparathyroidism in the elderly: consequences for bone loss and fractures and therapeutic implications. Endocr Rev 22 , $477-501$

88. Sai A, Walters R, Fang X, et al. (2010) Relationship between vitamin $\mathrm{D}$, parathyroid hormone, and bone health. J Clin Endocrinol Metab 96, E436-E446.

89. Gloth F 3rd, Tobin J, Sherman S, et al. (1991) Is the recommended daily allowance for vitamin $\mathrm{D}$ too low for the homebound elderly? J Am Geriatr Soc 39, 137.

90. Dixon T, Mitchell P, Beringer T, et al. (2006) An overview of the prevalence of 25-hydroxy-vitamin D inadequacy amongst elderly patients with or without fragility fracture in the United Kingdom. Curr Med Res Opin 22, 2, 405-415.

91. MacLaughlin J \& Holick MF (1985) Aging decreases the capacity of human skin to produce vitamin $\mathrm{D}_{3}$. J Clin Invest 76, 1536

92. Holick MF, Matsuoka LY \& Wortsman J (1989) Age, vitamin D, and solar ultraviolet. Lancet 334, 1104-1105.

93. Vieth R, Ladak Y \& Walfish PG (2003) Age-related changes in the 25-hydroxyvitamin $\mathrm{D}$ versus parathyroid hormone relationship suggest a different reason why older adults require more vitamin D. J Clin Endocrinol Metab 88, 185-191.

94. Bell NH, Epstein S, Greene A, et al. (1985) Evidence for alteration of the vitamin D-endocrine system in obese subjects. J Clin Invest 76, 370.

95. Bolland MJ, Grey AB, Ames RW, et al. (2006) Fat mass is an important predictor of parathyroid hormone levels in postmenopausal women. Bone 38, 317-321.

96. Snijder MB, van Dam RM, Visser M, et al. (2005) Adiposity in relation to vitamin D status and parathyroid hormone levels: a population-based study in older men and women. $J$ Clin Endocrinol Metab 90, 4119-4123.

97. Wortsman J, Matsuoka LY, Chen TC, et al. (2000) Decreased bioavailability of vitamin D in obesity. Am J Clin Nutr $\mathbf{7 2}$, 690-693.

98. Shapses SA, Lee EJ, Sukumar D, et al. (2013) The effect of obesity on the relationship between serum parathyroid hormone and 25-hydroxyvitamin D in women. J Clin Endocrinol Metab 98, E886-E890.

99. Macdonald HM, Mavroeidi A, Barr RJ, et al. (2008) Vitamin D status in postmenopausal women living at higher latitudes in the UK in relation to bone health, overweight, sunlight exposure and dietary vitamin D. Bone 42, 996-1003. 